\title{
Escola, oci i joves d'origen magribí. Segones generacions de famílies immigrades i el sentit de la seva inserció social. El cas de Mataró
}

\section{Miquel Àngel Alegre Canosa}

Universitat Autònoma de Barcelona. Departament de Sociologia

08193 Bellaterra (Barcelona). Spain

miguelangel.alegre@uab.es

\section{Diego Herrera Aragón}

Consorci Institut d'Infancia i Món Urbà (CIIMU)

dherrera@ciimu.org

\section{Resum}

Aquest article és fruit de la ponència presentada al III Congrés Català de Sociologia (Lleida, 20 i 21 de març de 1999), arran de la investigació realitzada sota el mateix títol al municipi de Mataró i finançada per la Fundació Jaume Bofill. El text aquí presentat situa algunes de les línies conceptuals que tradicionalment s'han resseguit per interpretar el sentit de la integració escolar de les segones generacions de famílies immigrades i alguns dels models que han orientat la seva posada en pràctica. Després d'apostar per l'anomenada "perspectiva asincrònica i intercultural», s’intenta definir el que segurament és el camp més trascendental per a la construcció de la identitat adolescent, l'oci.

Paraules clau: segones generacions, multiculturalitat, interculturalitat, escola, oci.

\section{Abstract. School, leisure and immigrant youth}

The article is the result of a communication presented at the III Congrés Català de Sociologia (Lleida, 20-21 March 1999). This communication comes from a research developed in Mataró under the same title and payed by Jaume Bofill Foundation. The text presents some ways to conceptualize the educative integration of immigrant children and some models that have deal with this project. We agree with the perspective we call «asincronic and intercultural». After that, the article proposes a definition of leisure, something that becomes a very important resource for the construction of the adolescent identity.

Key words: immigrant children, multicultural, intercultural, school, leisure.

\section{Sumari}

1. Introducció 4. A manera de tancament

2. Escola $\mathrm{i}$ «segones generacions»

5. Bibliografia

3. Oci i «segones generacions» 


\section{Introducció}

Ens inquietava, en iniciar aquest estudi, la manera com la defensa del dret a preservar la diferència cultural no pot acabar dificultant la consecució d'una autèntica igualtat (política, social i econòmica) entre els diversos grups socials (suposadament de base ètnica) i entre els individus, homes i dones, que els conformen. Retrobem, en aquest punt, el debat sobre els possibles «efectes perversos» de la retòrica antiracista multiculturalista. Del dret a la diferència al deure de conservar-la hi ha un petit salt discursiu, i, en canvi, dur-lo a terme pot resultar el millor mecanisme legitimador de la reproducció de les desigualtats socioeconòmiques i polítiques entre col-lectius diferents definits per l'adscripció ètnica. A efectes pràctics, tant és racialitzar com etnificar.

Reconduïda al camp del nostre específic objecte d'anàlisi, aquesta inquietud podria quedar traduïda en la pregunta següent: quin dret tenim a continuar anomenant els fills i les filles de famílies d'origen estranger «immigrants de segona generació», sense més ni més (com si la condició immigrada s'heretés)? Si pretenem que els descendents d'aquestes famílies puguin arribar a formar part integrant de la nostra societat, cal que aquests siguin considerats d'igual a igual amb la joventut d'origen autòcton. En altres paraules, cal que puguin disposar de l'autonomia de saber-se quelcom més que una mera extensió generacional d'una cultura ancestral que sovint desconeixen i que, en qualsevol cas, acostumen a no pretendre preservar a costa de quedar totalment segregats de l'espai social juvenil que estructura la societat autòctona. Emmenar-los a formar eternament part d'una pertitença ètnicofamiliar suposa fer un flac favor al dret d'aquests nois i noies de ser, simplement, «joves».

I ser jove, aquí i ara, és bàsicament donar sortida a un dilema bàsic: dedicació escolar versus participació en dinàmiques d'oci. Martínez ho explica amb unes altres paraules: "Per a la majoria dels joves estudiar implica obligació, control, càlcul racional, renúncia al present, ascesi i esforç. Ho associaré a l'“esperit del treball". Divertir-se, en canvi, implica per a la immensa majoria llibertat, plaer, emoció, viure el moment, hedonisme i sensualitat. En parlaré com a "esperit del consum". L'equilibri entre l'un i l'altre és un dels dilemes més importants en la vida dels joves, font de gran part dels seus maldecaps» (Martínez, 1998: 6). A l'entorn d'aquestes consideracions hem tractat d'abordar qüestions com ara: en quin sentit viuen els fills i les filles de famílies magribines la seva integració social?; com experimenten estar entre dues aigües, entre el marc referent familiar i el context a bastament socialitzador de la nova societat (escola, companys i companyes autòctons, mitjans de comunicació, hàbits culturals, etc.) quan la població i les institucions auctòctones sovint els obliguen a sentir-se com a part d'una cultura estrangera? Hem orientat el tractament d'aquests interrogants construint els que han estat els dos grans camps o contextos del nostre estudi: la institució escolar i la institució del consum ociós. 


\section{Escola $\mathbf{i}$ «segones generacions»}

L'escola no és l'única esfera institucional en què se socialitzen les joves generacions dels nostres dies, ni tan sols la més important. El context familiar, parental, comunitari, els anomenats "grups d'iguals», els mitjans de comunicació, etc., conformen espais de socialització tan transcendentals o més que el propi sistema d'educació formal i reglada.

Tanmateix, l'escola constitueix un camp de joc en el qual s'escenifiquen i es (re)creen dinàmiques socials específiques que informen les relacions interculturals ${ }^{1}$ establertes dins i fora de les aules. En paraules de Rex (1983), l'escolarització cristal.litza un "context segregador racial» en la mesura en què, per exemple, les pràctiques pedagògiques i curriculars quotidianes poden desorganitzar de forma sistemàtica les identitats de les minories ètniques en privilegiar la recontextualització de valors i racionalitats propis de la classe mitjana blanca.

A banda del que té a veure amb la mateixa configuració del currículum (genèric i projecte curricular de centre), a l'escola s'especifica la inserció social de les «segones generacions» en les interaccions d'aquestes amb professors $\mathrm{i}$ professores, amb companys i companyes de classe o de pati, en les relacions entre llurs famílies immigrades i els professors tutors, en particular, i entre aquestes i el centre educatiu corresponent, en general, així com amb les famílies d'alumnes autòctons o diversos serveis d'educació social i compensatòria. Tot plegat fa de l'escola una mena d'observatori privilegiat dels processos i els mecanismes que operen en les possibilitats d'integració social dels fills i les filles de famílies immigrades del Magrib.

La transcendència de l'àmbit escolar en relació amb l'objecte d'estudi proposat no tan sols es justifica des del pla analític. La pròpia realitat social s'entesta a fer-ne punt de referència obligada: mentre que, d'una banda, les autoritats receptores corresponents han desenvolupat instruments per no impedir de manera dràstica l'admissió d'aquests nens i nenes a l'escola per motius bàsicament de reproducció i legitimació socials ${ }^{2}$, les mateixes famílies immigrades majoritàriament aposten per inserir escolarment la seva descendència, atès que, en termes generals, pot dir-se que la sort del destí de la immigració com a fenomen social es juga en el futur d'aquesta segona generació ${ }^{3}$.

A la versió íntegra de l'informe d'aquesta recerca bàsicament s'ha tractat de dur a terme una triple tasca: 1) fer un breu repàs de les diverses solucions que, des de diferents tradicions teòriques i polítiques, s'han ofert a la problemàtica de l'escolarització de la diferència etnicocultural (solució neoconservadora,

1. Reservem l'ús del terme intercultural per referir-nos a la qualitat de l'educació que descrivim posteriorment.

2. Aquest aspecte hem tractat de posar-lo de manifest a l'informe complet de la investigació, en analitzar el marc legal que normativitza la presència a Catalunya d'aquestes «segones generacions» (apartat 2).

3. Segons afirma M. Siguán, aquest futur «quedará sellado con la tercera generación, bien en el sentido de la plena integración, bien en el de minoría tolerada o en el de minoría marginada y en conflicto» (Siguán, 1998: 12). 
solució liberal, solució multiculturalista, solucions neomarxistes, solució paral.lelista i solució asincrónica); 2) exposar els «tipus ideals» o models que han dirigit en el nostre sistema educatiu la qualitat d'aquesta inserció (model segregacionista, model assimilacionista i compensatori, model multiculturalista i model intercultural); 3) visualitzar de manera més empírica la distància que separa les escoles de Mataró (i més en concret els seus instituts) del model d'integració social pel qual hem optat: el de l'interculturalisme.

En aquest text pararem esment a dues solucions conceptuals que, tot i que resulten d'enorme interès, no han tingut prou ressò en el marc bibliogràfic més recorregut a casa nostra.

Posteriorment, ens detindrem a resumir la manera com entenem que cal construir el projecte intercultural, així com la traducció de l'interculturalisme al terreny dels models d'escolarització de la «diferència cultural».

\section{La solució paral.lelista}

Sota aquesta designació, Apple i Weis (1983) signifiquen els seus intents de donar resposta a preguntes del tipus: Com s'estructuren, prenen forma i es transformen les diferències ètniques en l'escolarització? En quina mesura interseccionen amb altres eixos de desigualtat com els de classe social o gènere en el medi institucional de les escoles? Com «integren» les institucions escolars les macrodinàmiques i microdinàmiques de la desigualtat?, totes aquestes qüestions no estan resoltes satisfactòriament per les solucions conceptuals abans esmentades.

Aquests autors critiquen la tendència dels teòrics del corrent dominant $\mathrm{i}$ de bona part dels adscrits a la crítica radical a escindir la realitat social en dos pols totalment independents: estructura i cultura; els primers consideren els valors i els prejudicis socioculturals (més o menys naturalitzats) com l'origen de l'antagonisme ètnic, els segons prioritzen la consideració de l'abast de les dinàmiques de classe per sobre de les d'ètnia o gènere. En contrast, Apple i Weis no consideren l'ètnia com una categoria estanca $\mathrm{i}$ indeleble, sinó un procés social íntegrament vinculat a d'altres dinàmiques socials que s'articulen en l'educació i en el seu entorn social. En concret, tres d'aquestes dinàmiques — de classe, de gènere i d'ètnia_-, irreductibles respecte de les altres, acaben esdevenint transcendentals en tota anàlisi de la vida social. Sense desmerèixer el paper que desenvolupa l'economia respecte a la determinació de l'estructura d'oportunitats i posicions a les societats capitalistes, els autors sostenen una visió de les formacions socials que amplia l'objectiu a dues esferes més, tan rellevants com la primera: la política i la cultural. D'aquesta manera, la postura paral-lelista planteja una teoria de determinació multiple, en la qual els processos i resultats desiguals de l'escolarització i, en general, la jerarquització social de tots els àmbits de la vida institucional s'expliquen en funció de les constants interaccions entre les tres dinàmiques o eixos de desigualtat (classe, gènere i ètnia) a cadascuna de les tres esferes considerades (econòmica, política i cultural). 
Des d'aquesta òptica antireduccionista pot abordar-se, per exemple, la interpretació de fenòmens com la sobreexplotació laboral de la força de treball d'origen immigrant (a la desigualtat classista s'hi afegeix l'ètnica, la qual cosa propicia la constitució d'una segmentació racial en el mateix segment laboral secundari), o, més proper al nostre objecte d'estudi, les baixes taxes de continuïtat escolar en el cas de les noies magribines en comparació amb la dels nois de la mateixa procedència i, encara més, amb la de nois i noies autòctons (al fet de pertànyer a un col-lectiu immigrant s'hi suma l'adscripció genèrica, d'aquesta manera s'opera un doble efecte de discriminació escolar).

Vet aquí les principals virtuts de la solució paral-lelista. No obstant això, cal no perdre de vista algunes de les seves limitacions. McCarthy n'assenyala dues: 1) la inadequació del model paral-lelista al nivell conjuntural d'anàlisi, i 2) el fet que aquesta perspectiva s'estructuri en un sentit estàtic i additivoincrementalista, entenent que de les dinàmiques de classe, ètnia i gènere es deriven impactes individuals, ininterromputs i acumulables, passant per alt els casos de tensió, contradicció i discontinuïtat en la vida institucional de l'ambient escolar.

\section{La solució asincrònica}

El concepte d'asincronisme neix de la crítica formulada per E. Hicks a la perspectiva anterior i a la seva tendència a analitzar les interrelacions entre les dinàmiques socials, com si aquestes fossin paral-leles, simètriques i recíproques. Des d'aquest punt de vista, les relacions entre els tres eixos de desigualtat no es reprodueixen sense problemes, ans al contrari, són complexes i fluctuants i sovint surten efectes contradictoris als mateixos ambients institucionals. Així, les interseccions entre els eixos de desigualtat en el micronivell de l'escola pot conduir a interrupcions, discontinuitats, increments i disminucions dels impactes que originàriament caldria atribuir a cadascuna de les tres dinàmiques.

Per aquest motiu, esdevé enormement complicat preveure la direcció i el caràcter dominants dels efectes d'aquesta amalgama de desigualtats sobre l'ambient escolar concret, això és, el principi o criteri articulador (classe, ètnia o gènere) del nucli hegemònic del conflicte. Segons McCarthy, la preponderància d'un criteri de conflicte o de l'altre dependrà de: «a) la mezcla concreta de historia, subjetividades, intereses y capacidades que los actores de las minorías y de la mayoría aportan al contexto institucional y b) el modo de negociar y fijar estos actores las reglas del juego" (McCarthy, 1994: 95). La pregunta que aleshores se'ns planteja és: quines són aquestes regles del joc en el context asincrònic de la institució escolar? Amb el benentès que no es tracta de regles independents entre elles, el mateix autor concreta les quatre següents:

1. Relacions de competició: remeten a la lluita per l'accés a les institucions educatives, oportunitats d'instrucció, credencials, recursos financers i tècnics, etc. 
2. Relacions d'explotació: derivades dels diferents i desiguals tipus de transició vers el mercat laboral que facilita l'escola d'acord amb les demandes de l'economia.

3. Relacions de dominació: en funció de la jerarquia de posicions i control simbòlic que l'escola, en tant que mediadora, acaba transmetent als seus alumnes.

4. Relacions de selecció cultural: les quals s'expliquen des de la mateixa definició del concepte de pedagogia segons B. Bernstein (1993): conjunt de regles distributives — que desgranen significats generals—, recontextualitzadores -que s'apropien d'alguns d'aquests significats per donar-los format escolar - $\mathrm{i}$ avaluadores — que converteixen aquests significars recontextualitzats en regles d'aprenentatge. Aquestes relacions seleccionen en funció de la distància dels alumnes i les alumnes i llurs famílies respecte d'aquestes regles.

Recapitulant: seran l'estructura del camp institucional escolar, la seva trajectòria, així com les estratègies derivades dels interessos i les subjectivitats dels actors implicats, els factors que en bona mesura donaran compte del principi articulador — classe, ètnia o gènere- que predomina en la determinació del conflicte i que defineix els antagonismes i les solidaritats, les quals prenen cos en les relacions de competició, explotació, dominació i selecció cultural que connecten l'escola amb la societat en què s'insereix. Per tal de veure la transcendència que té aquest model respecte a la construcció del nostre objecte d'estudi, tot seguit provem d'il.lustrar-lo amb un parell d'exemples.

És d'esperar que sigui en aquells centres escolars amb un nombre total d'alumnes força reduït i la seva gran majoria catalanoparlants, una bona coordinació quant al treball administratiu i directiu, amb un professorat molt avesat al contacte personal amb els alumnes i les alumnes i amb llurs famílies i amb una trajectòria marcada per l'absència de disfuncionalitats pel que fa a la tasca pedagògica normalitzada, on l'arribada d'alguns estudiants d'origen magribí pot suposar l'aparició d'un element que aglutini el conflicte i el debat sobre els diferents models d'escolarització de la diferència cultural (una diferència amb mancances educatives de partida). Per altra banda, en un altre centre amb multitud i «sobrecàrrega» d'alumnes i amb un alumnat accentuadament multicultural (concentració d'alumnes immigrats d'origen espanyol i d'origen estranger), caracteritzada per una llarga trajectòria d' "escola obrera», amb un funcionament administratiu ineficaç o desbordat $\mathrm{i}$ amb un equip docent $\mathrm{amb}$ poques inquietuds vers la problemàtica de la discriminació ètnica, difícilment els problemes que planteja l'escolarització de l'alumnat nouvingut poden erigir-se en el motiu fonamental del principi articulador del conflicte i de les relacions d'aliança i oposició de tota la comunitat escolar.

\section{El model intercultural. Obrint perspectives}

Malgrat el canvi d'orientació que ha anat prenent el Programa d'Educació Compensatòria i l'existència d'altres iniciatives innovadores en aquest sentit, 
es pot dir que en l'actualitat el model d'educació intercultural és encara una entel.lèquia en el context del sistema educatiu català. En aquest sentit, això ens permetrà en endavant formular la manera com entenem nosaltres que cal interpretar la noció d'interculturalitat. Òbviament s'ha escrit ja molt sobre el tema i s'han organitzat importants forums de debat al respecte — com és el cas de les dues escoles d'estiu sobre interculturalitat de Girona. Orientarem, doncs, la nostra perspectiva des d'algunes de les aportacions ja realitzades, si bé proposarem el que creiem que suposa una manera relativament nova de mirar-se la interculturalitat, valorant-ne les virtuts, els límits i alguns dels elements que determinen l'abast de la seva eficàcia. Es planteja un canvi d'enfocament, no tant l'exposició de continguts fins ara inexplorats.

Tal com s'afirma en el II Informe sobre immigració $i$ treball social de la Diputació de Barcelona, «són moltes les definicions que hi ha sobre educació intercultural» (1997: 651). El mateix informe cita la que dóna el Consell d'Europa (1986), la qual és molt útil al nostre propòsit: "[...] una pedagogia intercultural no és ni la juxtaposició d'assignatures culturals, ni la seva amalgama. L'objectiu que es persegueix no és la hibridació intel.lectual dels alumnes mitjançant una manipulació pedagògica, sinó l'enriquiment i la comprensió mútua per mitjà d'aprenentatges sobre el fonament cultural de cadascú [...], amb la finalitat que es respecti la pròpia cultura, es valori als ulls dels altres, i que la pràctica pedagògica se sustenti sobre una pràctica cultural en lloc de negar-les» (1997: 651).

Malgrat que encara existeix certa confusió a l'hora de fer ús de les nocions d'interculturalitat, multiculturalitat, àdhuc pluriculturalitat, sol entendre's que la diferència fonamental entre la primera $\mathrm{i}$ les altres dues rau en la importància que aquesta atorga al diàleg, a la interacció. Les cultures no són realitats estàtiques inamovibles, tal com suposen el «fonamentalisme cultural» conservador o el multiculturalisme més extremista als quals ens referíem amb anterioritat. Són processos que poc sentit tenen si no és en relació amb una alteritat, amb una diferència constantment reconstruïda davant de l'intercanvi, en uns termes o en uns altres. I és amb la voluntat de consolidar i enriquir aquests processos que precisament cal potenciar el diàleg cultural. Des d'aquest punt de vista, «l'educació intercultural vol significar un enfocament propositiu i expressa en si mateixa un projecte, un propòsit: l'establiment d'un marc de relacions on es faciliti la interacció cultural en un pla d'igualtat» (Lluch, 1995: 20).

En la línia de les propostes actuals en favor d'una escola coeducativa que subverteixi les tradicionals adscripcions de gènere i possibiliti la intercanviabilitat de diferents elements genèrics entre nens i nenes (algunes autores han parlat en aquest sentit de "desaparició dels gèneres»" ${ }^{4}$, l'escola intercultural pretén trencar la immutabilitat de les adscripcions ètniques i propiciar processos de mestissatge cultural.

4. Vegi's, per exemple, el llibre de Marina Subirats (1998). Con diferencia. Las mujeres ante el reto de la autonomía. Barcelona: Icaria. 
Un altre element que sol plantejar-se en aquest debat és el de la necessària extensió d'aquest tipus d'educació a tot el sistema docent. No es tracta d'un projecte que cal dur a terme tan sols en aquells centres on comença a ser significativa la presència d'alumnes de famílies immigrades. La interculturalitat pretén anar més enllà de la reactivitat que fonamenta la resta de models de tracte a la diversitat $i$, d'aquesta manera, arrelar les seves tesis en el nucli mateix de tot el procés d'escolarització. Les paraules de M. Siguán són clares en aquest sentit: el model intercultural proposa «una educación que no se dirige en primer lugar a los inmigrados sino a los autóctonos, y no sólo a los autóctonos que comparten las aulas con los inmigrados, sino también y sobre todo a los que no las comparten y que pueden el día de mañana discriminarlos» (Siguán, 1998: 132).

No n'hi ha prou amb la incorporació acadèmica d'afegits curriculars, ni amb l'organització ailllada d'experiències de foment de la tolerància i el respecte entre individus i grups (jocs, representacions, contactes epistolars, viatges, festes interculturals, etc.), ni amb la bona voluntat del professorat de cara a la generació d'un clima no hostil en les relacions interpersonals a l'aula, ni amb la col.laboració més o menys estable d'entitats i organismes que donen suport i assessorament a iniciatives solidàries a les escoles, ni tampoc amb l'elaboració de diferents plans d'acollida d'alumnes d'origen immigrat als centres escolars (plans, d'altra banda, certament escassos), etc. La interculturalitat reclama, en definitiva, un replantejament a fons dels valors i les pràctiques que informen l'educació formal en la nostra societat.

Per tal de dur a la pràctica l'extensió generalitzada a tot el sistema educatiu d'aquest replantejament, solen proposar-se iniciatives més concretes, com ara: conèixer $\mathrm{i}$ introduir visions favorables de les cultures d'origen de la immigració, fomentar un bon ensenyament dels drets humans, incorporar en tota transmissió de coneixements un component antiracista que permeti distingir el que són prejudicis del que són diferències culturals, formar el professorat en aquesta missió, revisar i modificar en allò necessari els materials escolars que es pretenen utilitzar per tal de buidar-los d'etnocentrisme, assolir la plena escolarització (lluitar contra l'absentisme i l'abandonament escolars) d'aquest alumnat immigrat, així com el seu total reconeixement legal, orquestrar mesures compensatòries com a darrera mesura i, especialment, orientades a resoldre els retards lingüístics d'aquests alumnes, etc.

Efectivament, totes aquestes iniciatives són necessàries per endegar l'anomenat "projecte intercultural». Però, alhora, cal no idealitzar l'abast que tot plegat pot tenir. L'educació intercultural és una condició necessària a fi de promoure el procés d'integració escolar i social de les segones generacions que aquí estudiem, així com de llurs famílies, però de cap manera esdevé suficient per a l'actualització d'aquest procés. I en aquest punt retrobem l'interès del debat que centren les diverses explicacions del paper que pot desenvolupar l'escola $i$, en general, l'educació en relació amb el context social en què existeixen. Així, per tal d'analitzar quin és l'abast d'una possible aplicació dels plantejaments de l'educació intercultural i quins són els corresponents elements 
que poden resultar determinants per fer-ho caldrà, primerament, explicitar com s'entenen les relacions que s'estableixen entre l'àmbit educatiu i el seu marc social i comunitari de referència.

És a dir, com definim nosaltres l'escola en el context del nostre objecte d'estudi?

L'escola com a institució social pot no ser un mer mecanisme de reproducció sociocultural de l'ordre establert, ans al contrari, un instrument relativament autònom i necessari en la lluita contra l'accentuació dels diferents eixos de desigualtat que creuen l'estructura social. Tanmateix, l'escola, en tant que realitat empírica i viscuda, s'insereix en el si d'una comunitat amb la qual entaula relacions de mútua determinació. Aquest context comunitari emmarca la situació en què es troba l'estructura creuada dels principals eixos de desigualtat (classe, ètnia i gènere), i és aquest panorama el que alimenta les relacions socials que s'estableixen a l'escola (alumnes-alumnes, alumnes-professorat, famílies-famílies, famílies-professorat, famílies-administració del centre, etc.). Ara bé, el mateix concepte d'asincronisme ens proporciona la pista de com pot invertir-se la direcció de la relació. Factors com la trajectòria i les inèrcies culturals dels mateixos centres, així com les estratègies derivades dels interessos i de les subjectivitats particulars i conjunturals dels actors implicats contribueixen a determinar el criteri que articula la visualització del conflicte i que, per tant, identifica els recursos que cal mobilitzar en la lluita. De resultes del desenvolupament d'aquesta lluita pot sortir transformada la pròpia estructuració de la vida comunitària. En tot cas, i per tal d'evitar la fragmentació d'aquest procés, escola i comunitat han de romandre en diàleg permanent: cal portar l'educació formal (l'escola) a la vida quotidiana (comunitat), de la mateixa manera que la comunitat ha d'incorporar-se a la vida escolar. I tot plegat sense perdre de vista el fet que aquest diàleg tan sols pot fructificar des de l'existència d'una igualtat d'oportunitats suficient com per poder, com a mínim, tenir accés a alçar la veu.

A la llum de la perspectiva proposada, enumerem tot seguit alguns dels elements que poden resultar determinants per facilitar l'actualització d'un veritable projecte d'educació intercultural:

\section{Sobre la qualitat de la incorporació de l'alumnat immigrat a l'escola}

Malgrat que és cert que aquest procés d'incorporació únicament pot donar-se per culminat «en la mesura que l'alumne migrant deixi de ser el centre d'atenció per part del professorat, en la mesura que el professorat i la resta de l'alumnat no siguin uns estranys, en el moment que passi a ser un més, quan tota la comunitat educativa té consciència del que es demana i del "paper» que li correspon desenvolupar» (Equip Escola i Diversitat, 1997: 53), en aquest punt ens referim a la transcendència que tenen els primers dies d'escola respecte al futur de la integració escolar (i social) d'aquest alumnat.

Des d'aquest punt de vista, si el que es pretén és tendir cap a una autèntica interculturalitat, cal evitar operar la incorporació per la via de la "recepció» freda i distant. És molt necessari que les escoles disposin d'un pla general ben 
coordinat que procuri l'«acolliment» en l'àmbit escolar dels alumnes i les alumnes d'origen immigrat. Cal implicar persones i organismes preparats al respecte, de dins de l'escola (equip directiu, tutors i tutores, docents) com de fora (professionals del PEC, del SEDEC, dels EAP, de les UAC, dels serveis socials municipals, equips d'experts independents), i imbricar les seves actuacions en el marc d'una planificació conjunta dissenyada alhora en vistes a les particularitats socials i geogràfiques de cada centre escolar. És més, aquest pla d'acollida no tan sols ha de ser ajustable a la realitat de cada escola, sinó també a la varietat de les situacions que pot presentar la incorporació d'aquests col.lectius. Algunes de les variables que acostumen a donar compte d'aquesta diversitat són: procedència de l'alumne (anant més enllà de la nacionalitat: poble o ciutat, àmbit rural o urbà...), situació familiar (persones amb qui conviu, situació legal, estudis dels pares i les mares, etc.), existència i tipus d'escolarització prèvia, domini de les llengües autòctones, moment de la incorporació (inici o no del curs, incorporació tardana o no), etc.

En aquesta línia, algunes escoles han dut a terme tasques com ara acompanyar el nen o la nena immigrada a l'escola, presentar-li l'entorn escolar i explicar-li'n algunes normes bàsiques, presentar als alumnes i les alumnes d'incorporació tardana o arribats a mig curs a la resta de companys i companyes de classe, orientar les famílies a l'hora de formalitzar la matrícula dels nens i nenes a les escoles i informar-los sobre el funcionament general del sistema educatiu, etc.; tot plegat amb l'ajut, en cas que sigui necessari, d'intèrprets, que solen ser membres de les famílies o, de vegades, els mateixos mediadors culturals.

El Programa d'Educació Compensatòria contempla determinades mesures en aquest sentit. En concret, el PEC promou i assessora l'elaboració d'un pla general d'acollida per a les escoles en el qual es dóna prioritat a la incorporació d'alumnes de famílies acabades d'arribar, en segon lloc als alumnes d'incorporació tardana i en tercer terme a les famílies nombroses 5 .

Sigui com sigui, cal emfasitzar la importància que té la manera com s'arbitra la incorporació d'aquests alumnes, en la mesura en què d'ella dependrà la construcció dels canals de comunicació entre la família immigrada i l'escola, així com entre la primera i les famílies autòctones. Efectivament, en nombroses ocasions, l'escola és la primera instància de caràcter oficial amb qui entren en contacte els pares i, sobretot, les mares d'alumnes immigrats. Cal, doncs, organitzar i planificar aquest primer contacte de manera que comenci a cons-

5. El problema continua essent el caràcter reactiu i subsidiari que ha marcat des dels seus orígens la trajectòria del PEC en aquest camp. Aquest programa actua en base a les sol.licituds de les escoles que conjunturalment en reclamin l'ajut, i molt poques són, a la pràctica, les que disposen d'aquests plans d'acollida. Les iniciatives i mesures del PEC no situen un marc general d'actuació extensible a tot el sistema educatiu català; fet que, al mateix temps, sol comportar efectes perversos des del punt de vista de la pròpia eficiència administrativa. Com s'afirma en el II Informe sobre immigració i treball social, "la inexistència de plans d'acollida fa que les escoles realitzin un major nombre de demandes puntuals, i que en conseqüència s'hagin d'augmentar les intervencions» (1997: 659). 
truir-se el necessari continuum família-escola. Així mateix, és la comunicació amb l'escola la que pot i ha de facilitar l'extensió de les relacions de les famílies $\mathrm{amb}$ altres instàncies autòctones oficials (serveis socials, entitats i programes d'ajuda, associacions de representació ciutadana, etc.).

\section{Sobre la qualitat de les relacions entre alumnes immigrats $i$ immigrades $i$ alumnes autòctons $i$ autòctones}

Si del que es tracta és d'afavorir el procés d'integració escolar i social d'aquests nens i nenes, esdevé del tot necessari marcar l'accent en la manera de fer-los partícips de les dinàmiques relacionals a partir de les quals els joves i les joves del nostre entorn construeixen la seva identitat.

És cert, com veurem més endavant, que l'escola és majoritàriament vista pels joves i les joves com un temps d'espera o d'inversió respecte a unes expectatives de futur, i que són fonamentalment els espais d'oci el territori més apropiat per articular les estratègies d'identificació i diferenciació que doten de sentit el seu present. Ara bé, resulta també poc qüestionable que l'escola no és només el lloc i el temps en què s'opera la recepció formal de coneixements reglats. En aquest espai, al pati de jocs, però també a les pròpies aules, els nois i noies construeixen la seva identitat integrant-se en uns grups i distingint-se d'altres.

Per aquesta raó, per exemple, és important analitzar la distribució i l'ús dels espais del pati de jocs. Majoritàriament, els mètodes d'intervenció en educació dissenyats per combatre les desigualtats per raó d'ètnia existents a l'escola han pres com a unitat bàsica d'anàlisi i canvi les aules. S'han dut a terme experiències de sensibilització de l'alumnat mitjançant l'organització de sessions extraordinàries adreçades a treballar la superació dels prejudicis interètnics, l'activació de processos d'empatia entre alumnes de diferents cultures, la potenciació de l'autoconcepte dels alumnes i les alumnes dels grups ètnics minoritaris, etc. Amb aquests objectius s'han desenvolupat activitats del tipus: lectura, anàlisi i discussió de contes desemmascaradors d'actituds xenòfobes, interpretació escènica de notícies que informen sobre injustícies comeses contra immigrats del Tercer Món, xerrades amb persones immigrades que n'han patit, visualització de vídeos educatius al respecte, etc.

Tot plegat són tasques interessants i que, malgrat que es duen a terme en el context de l'aula i de les sessions docents, llurs objectius pretenen assolir un canvi d'actitud en les relacions interculturals extensible a la resta d'espais de l'escola així com de fora del seu recinte. Creiem, això no obstant, que aquestes iniciatives haurien de prendre igualment en consideració la intervenció sobre l'espai que precisament representa l'escenari privilegiat en què els alumnes i les alumnes despleguen més lliurement (almenys en aparença) les estratègies d'identificació i diferenciació a les quals anteriorment feiem referència. Es tractaria, primerament, d'observar les pautes que guien tant l'ocupació i distribució de l'espai del pati com el moviment dels alumnes i les alumnes dins els seus límits. A què juguen (si juguen), amb qui ho fan, en quina mesura i 
sentit s'entaulen relacions de caràcter interètnic, quins nois i noies controlen l'apropiació dels espais del pati més ben valorats, quins queden relegats a la periferia, quins creuen d'un espai a un altre, amb quin objectiu, etc., són indicadors que cal tenir en compte en aquest primer moment. Posteriorment, convindria dissenyar mètodes d'intervenció dirigits a propiciar una distribució i uns usos de l'espai més equitatius i integradors entre alumnes autòctons i autòctones i alumnes d'origen immigrat ${ }^{6}$.

\section{Sobre la qualitat de les relacions entre alumnes i professor o professora}

En la mesura que la interacció entre l'alumnat a l'aula pot ser suscitada i, si més no, orientada, també el professorat (la seva preparació formal, així com la seva pràctica quotidiana en el tracte amb un alumnat multicultural) hi desenvolupa en tot plegat un rol determinant. D'aquí que haguem també d'emfasitzar la importància que suposa el grau en què els professors i, més particularment, el tutors acompleixen amb la seva triple escomesa d'esdevenir interlocutor, dinamitzador i model lingüístic per a aquest alumnat nouvingut.

En tant que interlocutor: «el mestre comparteix el tema a un nivell proper al de l'alumne. Intenta recollir la seva intenció comunicativa, les seves iniciatives, $\mathrm{i}$ intenta comprendre la comunicació en el registre en què l'alumne l'emet [...]. Hi ha intenció educativa, n'interpreta missatges incomplets, l'ajuda a completar-los, n'estimula els intercanvis verbals, etc.» (Arenes, 1995: 12).

En tant que dinamitzador: «el mestre utilitza recursos per conèixer i acostumar els alumnes a les regles del diàleg: respectar torns, escoltar l'altre, etc. Com a dinamitzador, relaciona uns alumnes amb els altres i orienta els seus intercanvis comunicatius d'una forma organitzada i intencionada" (ídem).

En tant que model lingüístic: "corrector subtil, adapta el seu llenguatge però no el deforma ni l'empobreix, sinó que el produeix en el registre que pot ser comprès i l'adapta, tant per copsar l'atenció de l'alumne com per fer-se entendre i facilitar-li l'adquisició de la nova llengua» (ídem).

Recordem, en aquest punt, la transcendència que per al futur escolar i, en conseqüència, social té l'anomenat «efecte Pigmalió». I no oblidem, tampoc, els impactes sobre l'estructuració de les desigualtats escolars per raó d'ètnia que poden ser motivats pel currículum ocult que transpira les relacions quotidianes entre ensenyant i alumnes. No en va, el conjunt de normes, valors i creences que informen la transmissió d'aquest cirrículum poden arribar a estructurar un

6. A hores d'ara no coneixem l'existència de projectes d'intervenció orientats en aquest darrer sentit. Cal començar a pensar-hi. I en aquest aspecte podria resultar de molta utilitat l'elaboració de materials i metodologies d'investigació-acció que han anat propiciant estudis i intervencions en el terreny de la coeducació i que, justament, destaquen el pati de jocs com una de les variables fonamentals que cal tenir en compte en l'anàlisi de les diverses relacions que estableix l'alumnat entre ell i amb el seu entorn, escolar i social. Vegeu, a tall d'exemple, les referències apuntades per X. Bonal i A. Tomé (1997) en el seu article «Metodologías y recursos de intervención» a Cuadernos de Pedagogía, 245, p. 56-69. 
aprenentatge paral.lel decisivament influent en l'autovaloració de nens i nenes $i$, per tant, en les actituds que aquests aniran prenent respecte al seu destí escolar i social.

A la llum d'aquestes consideracions, s'ha insistit ja molt en la necessitat que la docent o el docent disposi d'una adequada formació respecte de temes que afecten la presència escolar i social de l'alumnat d'origen immigrat. I entenem aital formació en un sentit ampli:

- En l'aspecte actitudinal. Sensibilització, respecte i valoració de la diversitat, voluntat d'escoltar i fer sentir la diferència, etc.; es tracta d'adoptar la ja esmentada «actitud de l'ignorant» que reclama Carbonell (1997) per al professional de la docència.

- En l'aspecte aptitudinal. Coneixements sobre el fenomen migratori (causes, polítiques d'immigració, itineraris migratoris, col-lectius migrants, problemes legals...), sobre la cultura d'origen de l'alumnat immigrat (religió, llengua, estructures familiars, tipus d'escolarització prèvia, hàbits alimentaris...), sobre les principals problemàtiques psicosocials d'aquest alumnat (desorientació, actituds de replegament en la cultura d'origen o, per contra, de negació de tot el que hi tingui a veure, agressivitat, inestabilitat emocional...), sobre els recursos pedagògics disponibles per millorar la seva inserció escolar (pràctiques pedagògiques adequades, control dels efectes dels propis prejudicis, materials didàctics adients, propostes d'organismes o programes externs a l'escola...), sobre els mecanismes i els instruments de gestió del conflicte intercultural, etc.

En tot cas, determinar que el destí de la inserció escolar d'aquest alumnat d'origen immigrat és plenament en mans de les actituds i aptituds del professorat suposa caure en la sobredimensionalització del seu paper que opera des dels plantejaments més ingenus del multiculturalisme. És evident que la inserció escolar arrela en l'assoliment d'un bon clima de relacions interpersonals en la quotidianitat de les aules. I en aquest aspecte, el professor o la professora pot esdevenir un important agent del canvi educatiu. Tanmateix, les seves accions són limitades per la pròpia trajectòria $\mathrm{i}$ les inèrcies culturals dels mateixos centres escolars, en general, i pel context institucional derivat de la particular configuració del currículum o projecte educatiu del centre.

\section{Sobre la importància del currículum (explícit) i del material escolar utilitzat}

Segons ha constatat G. Jovè i Monclús, «el currículum escolar és una de les eines més importants que cal tenir en compte en la institució escolar per tal de tenir present la pròpia cultura i potenciar el sentit crític de l'individu perquè reconstrueixi constantment aquesta cultura» (Jovè i Monclús, 1996: 40).

D'altra banda, i en la línia de les iniciatives curriculars que es plantegen des de la perspectiva asincrònica, entenem que, per tal de dur a la pràctica la configuració d'un currículum escolar intercultural, no són suficients les estratègies compensatòries neoliberals ni les propostes multiculturalistes d'addició 
periferica de continguts culturals diversos al currículum formal dominant. Amb l'objectiu d'evitar la fragmentació del currículum en currículums segregats en funció de l'adscripció ètnica, i propugnant que tot l'alumnat pugui tenir accés a un currículum acadèmic «bàsic» general, l'enfocament asincrònic es movia en la línia estratègica del que Connell anomena els «aprenentatges comuns». L'objectiu últim d'aquesta proposta consisteix a portar les experiències no institucionals de les minories immigrades al nucli mateix de l'organització i estructura del currículum dominant, universalitzant, per tant, la consideració de la diversitat cultural a tot el sistema educatiu. El que han de fomentar aquestes iniciatives és la subversió de les relacions de selecció cultural, competició, dominació i explotació que tenen cabuda en el marc curricular general del nostre sistema escolar, transformant-les en regles explícites que prioritzin la inclusió cultural, la cooperació i l'equitat, respectivament.

Un altre dels aspectes que cal tenir en compte per afavorir una educació que valori la diversitat, alhora que fomenti ponts de diàleg igualitari entre cultures diferents, és la manera com aquesta diversitat és introduïda al material escolar utilitzat i, més en concret, als llibres de text d'ús habitual. I el cert és que, si s'ha de jutjar pels resultats obtinguts per Caramàs i Garriga en la seva anàlisi de la imatge de l'islam als llibres de text, s'està encara prou lluny d'un marc curricular plenament intercultural (Caramàs i Garriga, 1996).

Desconeixem fins a quin punt aquests materials escolars han estat reelaborats amb la plena extensió de l'entrada en funcionament de la reforma educativa. Sigui com sigui, és de suposar que, malgrat la possible existència de certs esforços per introduir-hi millores, les inèrcies editorials i curriculars continuen contribuint a la reproducció d'aquests tipus de missatges transmesos mitjançant l'estructura i el contingut dels nostres llibres de text ${ }^{7}$.

Passi el que passi, el que en aquest cas no deixa de ser necessària és l'elaboració d'un pla d'actuació conjunt entre les administracions competents, les empreses editorials i els corresponents programes i entitats d'orientació i assessorament tècnic, amb la intenció de fer extensius els continguts curriculars de la interculturalitat a tot el material escolar utilitzat a les nostres escoles.

\section{Sobre la importància de l'aprenentatge de les llengües autòctones}

Cal insistir en la transcendència que la competència lingüística té a l'hora de facilitar o dificultar la integració escolar i, en general, social d'aquest alumnat nouvingut d'origen magribí. Bona part dels estereotips i prejudicis amb què la població autòctona percep aquests col-lectius i llurs famílies (des d'aquells que els atribueixen una inoperància intel-lectual i cultural indefugibles, a aquells altres que fonamenten afirmacions del tipus: «només volen parlar entre ells», «no els interessa relacionar-se amb nosaltres», en definitiva, «no es volen integrar»),

7. Dintre d'aquests esforços, cal considerar la posada en marxa per part del PEC de centres comarcals de recursos pedagògics dedicats tant a la programació i coordinació de criteris d'actuació sobre les escoles, com a l'organització de grups de treball per elaborar materials sobre temes concrets (acollida, lluita contra la xenofobia, etc.). 
troben la seva base de realitat - i, per tant, el criteri principal per a la seva desconstrucció- en res més que en la freqüent manca de domini de les llengües autòctones per part d'aquesta població.

En relació amb la inserció escolar d'aquestes segones generacions de famílies immigrades magribines, es fa evident que del grau de coneixement de les llengües autòctones vehiculars dependrà el seu futur acadèmic.

Es cert que en determinades circumstàncies poden reunir-se factors favorables a la consecució d'una immersió lingüística totalment satisfactòria. És, per exemple, el que els succeeix a aquells nens i nenes que, generalment per haver nascut aquí, s'incorporen al sistema escolar autòcton en edats molt primerenques (als quatre anys o fins i tot abans) i són rebuts al parvulari per la via abans exposada de l'«acolliment». Sense despreciar la seva llengua materna, se'ls procura fomentar la comprensió i la parla en la nova llengua en el context de les activitats lúdiques en què participen, de tal manera que en finalitzar l'etapa escolar són ja capaços i capaces de llegir-hi i escriure-hi. A partir d'aquí, «[...] en la medida en que reciba las enseñanzas en la nueva lengua, su competencia, tanto léxica como morfosintáctica, irá progresando de manera similar a como lo hace la de sus compañeros» (Siguán, 1998: 109). Alhora, aquesta competència comunicativa es veurà sensiblement reforçada per les relacions que aquests joves mantinguin fora de les aules, al pati de jocs i, sobretot, en espais d'oci, amb altres joves d'origen autòcton. Finalment, la pròpia actitud de les famílies sol ser força favorable perquè llurs fills i filles aprenguin i dominin com més aviat millor les llengües de la societat d'acollida. D’aquí que, encara que es mantingui la llengua materna com a llengua principal en el marc familiar, aquests fills i filles ja competents en la nova llengua vagin progressivament introduint-la-hi, de manera que sovint s'arriben a produir situacions com aquelles en què els fills i filles parlen català/castellà entre ells, àrab amb la mare i català/castellà o àrab amb el pare (atès que aquest sol tenir més contacte amb el món públic i productiu que la mare i sol requerir més que ella el domini de les llengües autòctones).

Però generalment la conjuntura no fa concórrer tot aquest seguit de circumstàncies favorables. En nombroses ocasions aquestes segones generacions s'incorporen de manera tardana a l'escola $\mathrm{i}$, en molts casos, ho fan un cop ja ha estat encetat el curs escolar. Alguns d'aquests nens i nenes no han estat escolaritzats prèviament, d'altres ho han estat de manera molt irregular i, en qualsevol cas, provenen d'un sistema educatiu —l'alcorànic, en la majoria dels casos - molt diferent del de la societat receptora. D'aquesta manera, sol succeir que el professor o la professora es troba a l'aula, freqüentment sense previ avís, amb alumnes que no entenen gens o pràcticament gens ni el català ni el castellà. És aleshores quan entren en escena les classes compensatòries organitzades pel PEC i/o les sessions d'educació intensiva del català que implementa el SEDEC.

Siguán ha criticat el fet que fins ara no s'hagi intentat realitzar «un análisis crítico de la manera en que funciona la educaciòn complementaria en el ámbito lingüístico y sólo se ha constatado una insatisfacción general entre los que 
se ocupan de ella y unos resultados más bien pobres» (Siguán, 1998: 111). Davant d'aquesta insatisfacció, l'autor assenyala com s'han començat ja a sentir veus que reclamen la solució francesa de les «classes d'acollida» ${ }^{3}$ (acueil), on els alumnes i les alumnes immigrats, sigui quina sigui la seva procedència $\mathrm{i}$ nivell d'escolaritat, se sotmeten a ple temps i, per tant, a banda de l'escolarització normalitzada, a un aprenentatge intensiu de la llengua, o llengües, del país receptor fins que no estan preparats per incorporar-se a les aules «normals». Aquesta solució, malgrat que pugui tenir certes virtuts, planteja principalment tres inconvenients que, segons el nostre parer, la fan desaconsellable en el context del nostre sistema educatiu: 1) visualitza i estigmatitza els grups que s'hi acullen reïficant l'associació entre dèficit i diferència cultural; 2) retarda l'aprenentatge de la resta de matèries impartides a les aules normalitzades, així com el contacte amb les dinàmiques escolars que transmeten coneixement informal, i 3) no assegura una equiparació completa de la competència lingüística entre alumnat immigrat $\mathrm{i}$ autòcton, en no poder penetrar en els àmbits comunicacionals d'aquests nois i noies fora de l'escola.

Lligant amb això, en el cas de Catalunya és planteja un segon agreujant que cal abordar sense embuts: no obstant la conveniència que la llengua escolar vehicular continuï essent el català també per als alumnes d'origen immigrat, convé no perdre de vista que la llengua autòctona que predomina en els seus entorns socials més immediats —-barri, llocs de treball...- és el castellà (a excepció feta d'algunes comarques). Sobretot en aquells nuclis amb una tradició industrial més arrelada (com és el cas de Barcelona i el seu cinturó industrial), la població autòctona amb qui primer entren en contacte les famílies immigrades sol provenir de la immigració interior, de la mateixa manera que els companys i les companyes d'escola de llurs fills i filles acostuma a tenir com a primera llengua el castellà.

Per tal de dur a terme, doncs, una actuació eficaç a les escoles en l'àmbit de l'adquisició lingüística, cal prendre en consideració les característiques socials dels barris d'on provenen els seus alumnes, així com la manera com té lloc la inserció de les famílies immigrades en el territori i en la comunitat.

\section{Sobre la importància del continuum entre escola i família}

D'acord amb el que abans esmentàvem, l'escola, en tant que institució social, pot no ser un simple mecanisme de reproducció sociocultural de l'ordre establert, ans al contrari, pot esdevenir un instrument relativament autònom i necessari en la lluita contra l'accentuació dels diferents eixos de desigualtat que creuen l'estructura social. En aquest sentit, i des del nostre posicionament, l'escola ha de promoure el canvi educatiu en favor de la plena igualació de les oportunitats de progrés escolar, combatent i invertint les desigualtats d'ordre escolar derivades de les desigualtats de tota mena que constitueixen la vida social i comunitària. A partir d'aquí, l'escolarització no pot limitar-se a repre-

8. Des del nostre sistema educatiu s'ha convingut a anomenar-les «classes pont». 
sentar el paper de mera corretja de transmissió del tipus de socialització que els alumnes i les alumnes reben en llurs respectives famílies; socialització que recrea les distàncies i les jerarquies existents entre famílies que ocupen posicions desiguals en l'estructura social.

Tanmateix, combatre aquestes desigualtats a base de fomentar l'enfrontament directe entre la pedagogia escolar i la familiar pot resultar contraproduent sense cap mena de dubte, i acabar esdevenint el criteri més eficaç a l'hora de perpetuar i legitimar les desigualtats a què es pretenia fer front.

Recordant Bernstein, les possibilitats d'èxit escolar de cada alumne poden ser en bona mesura explicades en funció del grau d'adequació existent entre el codi sociolingüístic d'ús predominant en el marc familiar i el codi educatiu que estructura el llenguatge del saber escolar.

De manera similar, estudis comparatius realitzats bàsicament des de l'òptica de la psicologia de l'educació donen compte de diversos factors que distingeixen famílies d'extracció social diferent i que poden determinar la consecució o no d'aquesta adequació entre socialització familiar i socialització escolar: 1) estructura familiar i rols (predomini d'un sistema rígid, autocràtic i patriarcal versus predomini d'una estructura democràtica, igualitaria i flexible); 2) actitud envers la vida i autoestima (fatalisme versus racionalisme, baixa confiança en un mateix i actituds passives versus molta confiança en les pròpies capacitats i actitud activa respecte a l'entorn); 3) relació amb la resta de la societat (desconfiança $\mathrm{i}$ inseguretat versus confiança i seguretat); 4) expectatives i orientació temporal (baixes expectatives i orientació d'objectius a curt termini versus expectatives elevades i orientació d'objectius a curt i llarg termini); 5) tipus de disciplina (càstig físic i immotivat versus disciplina suau i motivada); 6) tipus de comunicació (llenguatge poc abstracte i predomini de l'acció física versus predomini de la comunicació verbal abstracta); 7) estil d'ensenyament (estil negatiu, directiu, intrusiu i emocional versus estil positiu, indirecte, racional i adaptat a cada context situacional); 8) relació de la família amb l'escola (absència de respecte i estimulació sobre les matèries escolars versus respecte i estimulació sobre les matèries escolars, contacte infreqüent $\mathrm{i}$ indirecte amb l'escola versus contacte freqüent i directe) (Díaz-Aguado i Baraja, 1993, p. 45-48). En la mesura que la socialització familiar s'apropi al primer pol de cadascun dels paràmetres esmentats, més àmplia serà la seva distància respecte als criteris que reclama la socialització escolar. I la sospita és que la manera com té lloc la inserció en la comunitat i el territori de les famílies immigrades d'origen magribí no fa sinó consagrar la seva situació pròxima al pol que més les allunya de la pedagogia pròpia de l'educació escolar.

En aquest sentit, s'insisteix aleshores que quan el nivell de discrepància entre una pedagogia i l'altra s'allunya d'un determinat punt òptim', poden

9. Efectivament, la psicologia cognitiva s'ha esmerçat a justificar que el rendiment i la realització del potencial d'aprenentatge (del «nivell de desenvolupament potencial» en paraules de Vygotsky) es veuen afavorits quan el subjecte afronta nivells de discrepància moderada entre allò que se li presenta i allò que coneix. 
crear-se obstacles seriosos a l'aprenentatge, atès que "puede llegar a identificarse el éxito en la escuela con el desprecio por la herencia y los propios padres, y puede llegar a identificarse el fracaso escolar con la resistencia ante la injusticia» (Cole i Stribner, citat per Díaz-Aguado i Baraja, 1993: 34).

En el cas de les famílies d'origen magribí sembla introduir-se una condició de dissonància addicional: «són d'una altra cultura».

La solució, repetim, no passa per reproduir a l'escola els esquemes socialitzadors de les famílies en qüestió. Del que es tracta, en primer terme, és d'aturar-se a analitzar fins a quin punt aquestes discrepàncies addicionals entre els dos tipus d'educació no es deuen al desconeixement mutu entre l'escola i les famílies d'origen magribí. És llavors quan, per exemple, aparents desavinences culturals poden manifestar-se com a simples malentesos.

L'exemple més il.lustratiu d'aquesta qüestió: «Algunos maestros se quejan de que los inmigrantes magrebíes se desentienden completamente de la educación de sus hijos en todos los aspectos. En Marruecos, y en el mundo islámico en general, la familia delega en el profesor prácticamente todo y considera que éste se hace responsable de la educación integral de su hijo" (El País, 10 de novembre de 1998: 40) ${ }^{10}$.

Molt probablement, les diferències irreconciliables entre tots dos mons seran moltes menys de les que en un principi s'hagués suposat. I quan aquestes apareguin (certament no neguem la seva existència), serà el moment de la negociació, de la necessitat d'arribar a un acord que respecti, sense construir murs de separació, totes dues esferes de socialització. En altres paraules, cal incorporar les famílies al diàleg intercultural que reclamem a les escoles. Altrament, tan sols s'acaba traumatitzant el procés d'escolarització dels alumnes $\mathrm{i}$ les alumnes d'origen immigrat $\mathrm{i}$, en general, dificultant la pròpia integració social de llurs famílies.

\section{Oci i «segones generacions»}

Arribats en aquest punt, ens endinsarem en el camp de l'oci juvenil per tal de conèixer el paper que desenvolupen les seves dinàmiques en el procés d'integració dels fills i filles de famílies magribines. Tal vegada sigui aquest l'aspecte més estrictament nou pel que fa a l'estudi de les segones generacions de famílies immigrades. I per què considerem l'esfera de l'oci com a quelcom de forçosa

10. Encara un segon exemple: «¿Cómo se explica que algunos padres de alumnos de origen magrebí no entiendan que la música juega un papel importante en la enseñanza y que es necesario que sus hijos practiquen algun tipo de ejercicio físico? Se tiende a atribuir esta actitud a prejuicios de tipo religioso, culpando al islam de esta supuesta aberración. En ocasiones es así, pero, a menudo, las razones son otras; resultado de una percepción cultural enraizada en la tradición y en el origen de estas familias. La mayoría de estos inmigrantes proceden del mundo rural, donde la música está asociada a las fiestas tradicionales y el ejercicio físico no tiene sentido en sí mismo. A los padres se les hace difícil aceptar que el estudio sea compatible con la fiesta y que sus hijos tengan que deslomarse gratuitamente» ( $E l$ Pais, 10 de novembre de 1998: 40). 
referència en aquest treball? En vista de recents aportacions sociològiques sobre la qüestió, entenem que l'espai de l'oci, atès que estructura bona part dels processos de construcció de la identitat dels joves i les joves, esdevé fonamental en la dinàmica d'inserció social d'aquest col-lectiu. Així, «la cultura juvenil, la cultura de l'oci, no és una inversió [com ho seria l'educació formal] sinó un consum que proporciona gratificacions i coneixements immediats, i per això és el territori més adient per portar a terme aquelles estratègies d'identificació i diferenciació que intentaran convertir l'accidentalitat del procés juvenil en quelcom de substancial» (Martínez i Pérez, 1998: 86).

Com ja havíem fet en referir-nos al paper de la institució escolar (més en concret, al de les relacions amb l'entorn familiar i comunitari), en el procés d'inserció de l'alumnat d'origen immigrat, explicitem ara sintèticament el nostre posicionament respecte al rol que desenvolupa el consum d'oci en l'articulació d'aquest mateix procés. Ras i curt: l'oci és bàsicament allò que posen en circulació i intercanvi les dinàmiques de consum dels joves i les joves. I aquestes dinàmiques són, al seu torn, les que fonamentalment omplen de contingut el continent que moldeja la joventut en tant que trànsit o temps de resolució vers l'etapa adulta de la vida. En consequiència, són els temps i els espais adreçats al consum d'oci els que doten de significat el present dels nois i noies, atès que la dedicació a l'educació formal reglada acostuma a no ser vista com a res més que una inversió, que un temps d'espera, únicament justificable en funció d'unes expectatives de futur. Atesa la reduïda participació dels joves i les joves actuals (sobretot dels adolescents i les adolescents en edats com les aquí tractades) en dinàmiques laborals, d'acció política o d'intervenció públi$\mathrm{ca}$, el consum d'oci és el que acaba configurant la joventut com a etapa plena i diferenciada de la vida. Aquest consum no tan sols proveeix identitat juvenil, sinó que ho fa mitjançant la integració en un sistema de consum (i en un estil) i, per tant, també a través de la construcció d'alteritats quant a conjunts estilístics es refereix. Els paràmetres del consum d'oci dels individus s'emmarquen en l' «univers dels possibles», determinat per la seva ubicació en l'estructura social de classe, sexuada i etnificada. Per aquesta raó, consumir no és un acte d'autoafirmació plenament lliure i autònom, sinó que respon en bona mesura a uns condicionaments d'ordre material. Al mateix temps, l'acte del consum posa en marxa mecanismes de diferenciació dels quals poden valer-se els joves i les joves per identificar-se i fer-se amb una posició, en ascendència $o$ descendència, en l'espai social juvenil. És precisament aquest el motiu pel qual trobem transcendental valorar la mesura i el sentit en què les segones generacions estudiades participen del consum ociós. En altres paraules, si consumir oci juvenil és ser jove, aleshores cal analitzar la inserció d'aquests nois i noies d'origen magribí en les dinàmiques d'aquest consum, no en va estan en joc la seva consideració en tant que joves, el seu dret a ser-ho i, per tant, les seves possibilitats d'integració social (i no tan sols escolar).

Un cop feta explícita la manera com creiem que cal conceptualitzar el sentit dels consums d'oci, n'exposem tot seguit aquelles dimensions considerades rellevants per copsar l'abast de les dinàmiques que aquests consums fan entrar en joc. 
Hem conceptualitzat aquestes dimensions en forma de dicotomies que centren tota una sèrie de continuums, amb la intenció de veure quins espais d'aquests ocuparien els joves i les joves d'origen magribí.

\section{Oci a casa, oci fora de casa}

El sentit comú i també les ciències socials han acostumat a donar compte de les diverses activitats i dels diversos espais integrables sota el terme oci fent ús de la divisió següent: oci passiu, oci actiu. Les activitats d'oci passiu són, per exemple, veure la televisió, escoltar música, llegir premsa, participació en l'«alta cultura", etc., mentre que la pràctica d'hàbits com anar a passejar amb amics o amigues, anar junts al cinema, practicar esports, sortir a jugar al carrer, a prendre algun refresc, sortir de "marxa», anar «de copes», a ballar..., hauria d'ésser inclosa sota la definició d'oci actiu.

Ara bé, el nostre punt de vista sobre l'oci juvenil no suposa, ans al contrari, una relació passiva i estàtica (per tant, alienant) amb l'objecte consumit. Tot consum d'oci, també mirar la televisió o llegir còmics, posa en joc la capacitat de «bricolatge» dels joves i les joves, la seva participació activa en la descodificació, selecció, recontextualització i resignificació dels productes estilístics que proporciona el mercat de masses. És per aquest motiu que hem optat per organitzar el discurs i la informació obtinguda del treball de camp en base a dues categories alternatives: consum d'oci a casa (s'entén, a la llar familiar) i consum d'oci fora de casa. Efectivament, aquesta classificació, que pretén buidar de contingut valoratiu l'anterior, tanmateix no troba correspondència directa quant a la divisió d'activitats d'oci en les dues categories. És a dir, ni totes les pràctiques ocioses realitzades a l'àmbit domèstic poden, des dels paràmetres anteriors, ser considerades com a passives (a casa es poden praticar jocs, xerrar amb amics o amigues, organitzar festes, etc.), ni totes les activitats de lleure fora de casa responen als criteris de l'oci actiu (és el que succeeix, per exemple, amb la participació en l'«alta cultura», o quan se surt a llegir al carrer, etc.).

A banda de superar les limitacions atribuïdes al criteri classificatori «oci passiu/oci actiu», l'enfocament que plantegem troba justificació teòrica en el fet que de la mateixa manera que adquireixen un significat diferent les dinàmiques d'oci quotidià, les del cap de setmana, del diumenge o de les vacacances, l'espai transmet un valor social diferent a l'oci de la llar, del barri, del centre, de la ciutat, de l'escola, etc. Cadascuna d'aquestes unitats espacials i temporals conté una dinàmica pròpia i dóna lloc a diferents intensitats i modalitats estratègiques a l'hora de viure i practicar el lleure ${ }^{11}$.

11. Concretament, val a dir que l'espai urbà (escola, espais i locals públics, entitats de lleure, residència, barri, etc.) ofereix a la població jove tres significats distints de l'oci: distància, instrumentalitat i entorn social (Olabuénaga, 1996: 91). A les zones periferiques de les nostres ciutats industrials, per exemple, on es concentren gran part de les macrodiscoteques $\mathrm{i}$ de l'oferta lúdica actual, l'oci es recolza en el valor de la distància física i simbòlica respecte de la llar i la vida quotidiana i és viscut com una ruptura. 
En particular, proposem aquesta categorització perquè entenem que assenyala de manera directa l'abordatge d'una de les funcions principals del consum d'oci: la dotació d'identitat en el joc de les relacions grupals juvenils. És cert que el sol fet de consumir, des de l'òptica plantejada, proporciona elements per a la construcció creativa d'un estil, d'una «estètica arrelada» (Willis, 1998) propis, també és poc qüestionable que allà on els joves i les joves diluciden la seva integració en l'univers prototípicament juvenil $i$, en conseqüència, el manteniment de la seva identitat com a tals, és en l'anomenat «camp de joc juvenil», en l'espai d'encontres i desencontres que estructura l'entramat de les seves interaccions. D'aquesta manera, entenem que és bàsicament la participació en activitats d'oci fora de casa el procés que permet l'actualització d'una identificació juvenil duradora.

En definitiva, i pel que fa en aquest punt, la línia argumental que hem tractat de resseguir per donar compte de la realitat empírica del cas mataroní, ha girat a l'entorn de la tesi següent: els joves immigrats tenen un accés més restringit en comparació als autòctons als espais d'oci fora de casa més visibles i més ben valorats socialment, de la mateixa manera que les joves immigrades troben, més que no pas llurs homòlegs masculins, les portes tancades a la plena participació en activitats d'oci fora de casa. Sense negar el fet que les joves puguin dotar-se de sentit identitari dins les fronteres de la llar familiar (precisament, entendre que també aquest oci suposa creativitat ens permet d'afirmar-ho), i per tant la possibilitat que la cultura juvenil femenina pot perfectament sustentar-se en una "cultura de dormitori» (Wulff, 1988), tanmateix estem d'acord amb les paraules de Feixa: «la reclusión femenina en el espacio doméstico las ha alejado de la calle o de los locales de ocio, espacios privilegiados de las culturas juveniles» (Feixa, 1998: 20). Com veurem en el darrer dels punts que segueixen, aquesta relegació a espais d'oci poc invisibles esdevé encara més determinant en el cas de les noies magribines.

\section{Oci intracultural, oci intercultural}

D'acord com enfocàvem la consideració de la qualitat de les relacions entre alumnes immigrats o immigrades $\mathrm{i}$ alumnes autòctons o autòctones que tenen lloc a l'escola (al pati de jocs, però també a les aules i passadissos), entenem que si el consum d'oci pot afavorir la integració social d'aquestes segones generacions $\mathrm{i}$, d'aquesta manera, pot revertir en dinàmiques no reproductores de la seva posició social, aquest ha de desenvolupar-se en espais que posin en interacció joves immigrats o immigrades i joves autòctons o autòctones. Altrament, en la mesura en què s'operen dinàmiques d'oci guetitzades (únicament intraculturals) i, en conseqüència, de replegament, es facilita que aquestes acabin impedint l'articulació de processos que trenquin amb la reproducció cultural de les disposicions d'aquests jovent, instrument idoni per a la perpetuació de les posicions estructurals.

Tanmateix, oci intercultural no implica necessàriament oci intercultural. Efectivament, compartir espais comuns, àdhuc que existeixin relacions entre 
grups culturalment diferents, no sempre comporta una participació integrada en grups d'oci caracteritzats pel mestissatge. En altres paraules, la veritable integració dels joves i les joves d'origen immigrat en les esferes del consum d'oci que poden proporcionar una identitat social juvenil estable té lloc quan participen en tant que «iguals» dels consums de grups multiculturals. En tot cas, si bé l'existència d'espais d'oci intercultural no és condició suficient per a la consecució d'aquest procés, sí que suposa un requisit necessari per possibilitar-lo.

Per aquest motiu, i pel que fa a la consideració del cas dels joves i les joves mataronins i mataronines de secundària, ens hem hagut de referir a la mesura i el sentit en què aquests nois i noies d'origen immigrat són presents en els mateixos espais d'oci que els nois i noies autòctons, comparteixen amics de procedència diversa (nacional o estangera), s'identifiquen amb la realització de les mateixes pràctiques de consum que estructura la joventut no immigra$\mathrm{da}$, combinen de la mateixa manera la dedicació a l'escola i la dedicació al lleure, etc. ${ }^{12}$.

Retrobant, novament, la dimensió segmentadora de l'accés als consums d'oci, la tesi sobre la qual ha girat l'organització de la informació extreta del treball de camp corresponent a aquest punt dirigeix l'atenció sobre la participació desigual de joves immigrats i joves immigrades en les dinàmiques relacionals que es configuren en espais d'oci interculturals. És a dir, les noies immigrades no tan sols tenen un accés més restringit que els nois a l'oci fora de casa; quan surten de l'àmbit domèstic consumeixen el lleure en espais molt guetitzats. En relació amb els nois immigrants, creiem que pot presumir-se que, tot i ser més presents que les noies en espais d'oci intercultural, el grau d'integració en dinàmiques de consum interculturals contiua essent força baix.

\section{Oci formalitzat, oci menys formalitzat}

A nivell analític, i ni que sigui a força de simplificar la complexitat que es dóna realment en la pràctica quotidiana, podem igualment classificar les dinàmiques d'oci segons el seu grau de formalitat. Totes les activitats de lleure tenen lloc enmig d'unes coordenades espacials i temporals a través de les quals adquireixen significats diferents. Com hem vist, les activitats d'oci protagonitzades dins

12. Convindria introduir un element corrector a fi de relativitzar en certa manera el possible impacte que sobre el posicionament en l'estructura social pot arribar a ocasionar la integració d'aquestes segones generacions en dinàmiques interculturals de consum d'oci: en general, l'extracció socioeconòmica dels joves i les joves enquestats i/o entrevistats no difereix de manera ostensible en funció del seu origen magribí o autòcton. Per aquesta raó, més que no pas les possibilitats de superació de la desigualtat per raó de classe social, el que està en joc és la construcció de la identitat d'aquest jovent immigrat a l'entorn dels paràmetres del que suposa la condició juvenil a la nostra societat; a partir d'aquí, i en aquest punt rau una de les sospites que se'ns ha suscitat al llarg de la redacció del nostre treball, la «normalització» de la sociabilitat de les segones generacions pot, al contrari del que sovint s'afirma, arrossegar llurs famílies vers trajectòries parl-leles d'integració social. 
la llar i el consum d'aquest al barri, al parc, a les grans superfícies comercials, etc. (així com també el característic dels caps de setmana, el dels dies d'escola o el de les vacances de Nadal, per exemple), contenen una dinàmica pròpia i donen lloc a diferents modalitats a l'hora d'experimentar i omplir simbòlicament el temps lliure per part dels joves i les joves. De la mateixa manera, les activitats que es practiquen de forma espontània al pati de jocs, al carrer de casa o al parc del barri tenen pels nois i noies un significat clarament diferent respecte a aquelles altres que estan fortament condicionades, si no determinades, per un alt grau de direccionalitat més o menys explícit (com succeeix en el cas de les activitats extraescolars organitzades pel propi centre d'ensenyament o aquelles altres que es desenvolupen en acadèmies o institucions diverses) ${ }^{13}$.

La nostra proposta teòrica consisteix ara a proporcionar orientacions que ajudin a distingir les activitats d'oci en funció de la seva ubicació dins l'eix que anomenem «activitats formalitzades/activitats menys formalitzades» 14 .

D'una banda, i en un extrem de l'eix, situaríem aquelles dinàmiques de lleure en les quals els joves i les joves s'han vist desplaçats del seu paper de protagonistes perquè les persones adultes han agafat el control. Són les que hem anomenat «activitats formalitzades». Sense possibilitat de poder (re)definir, dins de certs límits, les regles de joc segons els seus propis criteris i interessos, aquestes activitats esdevenen pels joves espais ordenats i controlats institucionalment, on només poden desenvolupar un paper més aviat d'audiència, de continent, i no tant de participants «actius». En efecte, activitats com ara les classes d'idiomes, de mecanografia, d'informàtica, o fins i tot aquelles altres organitzades per institucions específiques d'educació en el temps lliure (grups d'esplai, ludoteques, colònies d'estiu, festes organitzades pels centres escolars, equips esportius, etc.) poden perdre per alguns joves la seva originalitat, la seva creativitat, la seva vessant com a camp de descoberta, de cultiu, de manifestació d'interessos, d'innovació, etc., en la mesura en què, a més d'ésser regides per normes inamovibles, estan fortament determinades per marcs físics (l'escola d'idiomes, l'acadèmia, el casal, les instal.lacions esportives) i blocs temporals (l'horari) fixats a priori.

13. Hem optat per parlar d'activitats menys formalitzades, i no pas d'activitats no formalitzades o informals, perquè entenem que no existeixen activitats «lliures» de constrenyiments. Partint de la base que les relacions entre les persones no poden tenir lloc en un buit social, sinó que sempre s'estableixen enmig d'un marc estructurat i estructurador de l'acció, pensem que la interacció que els joves i les joves estableixen entre si en el seu camp de joc (seguint la terminologia bourdeuana) està triplement condicionada per llur ubicació en l'espai social, per les regles de joc pròpies de cadascuna de les activitats d'oci i, finalment, per la construcció mútua de representacions sobre l'altre que, de fet, també influeixen sobre les constriccions de caire estructural (de manera que també s'han de tenir en compte els condicionaments derivats del treball simbòlic si desitgem entendre i explicar les lluites quotidianes, individuals i col-lectives que esdevenen enmig d'aquestes estructures).

14. Pel fet de tractar-se d'un continuum donem per descomptat que les activitats situades als seus extrems no són més que tipus ideals que mai no es donen en «estat pur»; tanmateix, el mèrit d'aquest instrument d'anàlisi rau en el fet que ens permet reconèixer una activitat com a més o menys formalitzada a través de la comparació. 
D'altra banda, i a l'altre extrem del continuum, tindríem aquelles activitats de lleure que els nois i noies poden fer-se pròpies, aquelles dinàmiques susceptibles d'ésser manipulades i carregades de sentit a partir de la implicació d'aquests en la seva configuració. Són les activitats que configuren l'«autèntic» camp de joc juvenil i que permeten elaborar i mantenir la identitat dels joves i les joves com a tals. Xerrar amb els amics i les amigues del barri al carrer, jugar al pati de jocs, intercanviar cassets i gravar-ne, fer manualitats o jugar amb la consola són activitats que els nois i noies duen a terme i orienten amb més autonomia i que ofereixen més possibilitats per (re)elaborar simbòlicament els productes que el mercat de l'oci colloca al seu abast. En paraules de Paul Willis (1998), el fet que el jovent pugui donar sentit a les seves activitats culturals i, per extensió, a les seves dinàmiques de lleure, és la garantia que es puguin establir «contactes espurnejants» $\mathrm{o}$, com diu també, "contactes simbòlics vigoritzants» i contribuir, així, a la construcció de significats propis i de productes culturals «arrelats» com a part de l'experiència quotidiana, al marge del monopoli de les institucions. És precisament aquesta possibilitat de construir els perfils de la pròpia activitat per mitjà dels usos simbòlics dels seus productes el que possibilita en una mesura més elevada que les pràctiques d'oci estructurin bona part dels processos de construcció de la identitat dels nois i noies, i que esdevinguin fonamentals en la inserció social d'aquest col-lectiu a través de la confecció de xarxes de sociabilitat amb el seu grup d'iguals.

De la mateixa manera que hem fet als epígrafs anteriors, en aquest hauríem de referir-nos també a la vessant discriminatòria de l'oci en tant que esfera reproductora-productora de les desigualtats socials de tot tipus (de gènere, de classe social i de la seva subrogació, la d'ètnia). En canvi, considerem que la dimensió segregadora de les activitats ocioses en funció del seu grau de «formalització» no s'imposa sinó a través d'un altre eix transversal («oci instructiu versus oci (re)creatiu») que estableix la seva verticalitat en cadascuna de les dinàmiques de lleure. És per això que prorroguem fins al punt següent les orientacions teòriques sobre com el lloc ocupat per cadascun dels individus determina les seves possibilitats reals d'accés a un tipus d'oci o a un altre (més o menys formalizat i de tipus instructiu o bé (re)creatiu).

\section{Oci instructiu, oci (re)creatiu}

Des del nostre punt de vista, també contemplem com a ocioses aquelles activitats que guarden més paral-lelismes amb les dinàmiques característiques del marc escolar (classes d'idiomes, d'informàtica o mecanografia, de música, etc.), i no només aquelles altres de tipus lúdic o (re)creatiu, més o menys formalitzades, que esdevenen aparentment lliures de normes i constrenyiments (jocs audiovisuals, diversions al carrer, grups d'esplai, festes privades o populars, competicions esportives, etc.). Sense negar el fet que les activitats instructives són un recurs sobretot formatiu o una inversió, i que la seva realització pot suposar als joves i a les joves (o almenys a una part d'ells o d'elles) dificultats a l'hora de posar en pràctica estratègies d'identificació i diferenciació tan efica- 
ces com les que entren en joc quan s'és protagonista de dinàmiques de tipus recreatiu, no deixa de ser significatiu per considerar-les com a activitats ocioses el fet que tenen lloc fora de l'estricte marc escolar, així com el caràcter voluntari de la seva pràctica ${ }^{15}$.

En termes generals, i a diferència d'aquelles activitats properes a l'imaginari formatiu o escolar, les dinàmiques d'oci (re)creatiu no són viscudes per alguns joves o algunes joves en termes d'inversió o com a temps d'espera, ans al contrari: són la condició del seu present. La participació en la modalitat d'activitats menys instructives té un valor positiu en l'imaginari juvenil, ja que permet dilucidar amb més eficàcia i amb més marge de maniobra la seva integració en l'univers juvenil i posar, per tant, en acció un joc de relacions susceptible de convertir-se en un símbol de distinció social. La dedicació a activitats que guarden una distància prudent, física i simbòlica, respecte d'aquelles altres de caire més instructiu, facilita als individus entrar en dinàmiques d'estructuració de la identitat a través de la tria d'espais, d'elements estètics i culturals, d'amics, de coses que cal fer, etc. Tot plegat suposa la posada en escena de dispositius que reforcin, d'un costat, la identificació amb un estil de vida juvenil i el grup propi (endogrup) i, de l'altre, el distanciament respecte a la resta de col.lectius socials juvenils (exogrups).

La més gran dedicació a un tipus d'activitat o a un altre pot ser un reflex evident de les condicions objectives d'existència en les quals es desenvolupa la vida quotidiana dels joves i les joves, és a dir, de llur ubicació en el creuament de les desigualtats de tipus socioeconòmic. En aquest sentit, apuntem la idea que els individus pertanyents a aquelles famílies amb un capital econòmic i cultural més gran tendiran a desenvolupar amb més freqüència activitats formalitzades relacionades amb l'imaginari escolar en relació amb aquells altres ubicats en posicions socials menys privilegiades. La interpretació que puguin fer sobre la joventut els pares i les mares dels nois i noies més ben situats com a temps d'inversió i preparació per a la futura entrada en el món dels adults, explica que aquests joves tinguin tots els números per dedicar el seu temps lliure a desenvolupar activitats dirigides que tinguin a veure amb aprenentatges de tipus acadèmic o que complementin la formació rebuda a l'escola.

L'altra cara de la moneda està constituïda per aquells joves les famílies dels quals es mouen pels espais menys centrals i estratègics de l'estructura social. El fet que les expectatives de posicionament social de partida de moltes d'aquestes famílies respecte als seus fills i filles ja resultin ser baixes pot determinar, juntament amb l'escassetat de recursos econòmics, que molts d'aquests joves omplin el seu temps lliure amb el consum d'un oci més lúdic o de tipus (re)creatiu (precisament aquell que pot tenir lloc al carrer, en els parcs i des-

15. Al llarg de les entrevistes amb els nois i noies de Mataró, hem pogut constatar com la gran majoria d'ells i elles han triat llurs activitats extraescolars (cursos d'idiomes i mecanografia, classes de gimnàstica, entrenaments de futbol, etc.) guiats pels seus gustos i interessos (acadèmics i/o de lleure). 
campats, al camp de futbol del barri, etc., encara que també a casa: veure la televisió, jugar amb la consola, amb els germans i germanes, etc.) ${ }^{16}$.

Partint d'aquesta idea, i tenint en compte que moltes de les famílies dels joves i les joves autòctons considerats en el nostre estudi no gaudeixen pas d'unes condicions materials substancialment millors que aquelles altres procedents dels països magribins, la idea a partir de la qual hem interpretat la informació recollida al llarg del nostre treball de camp pel que fa a aquest punt és la següent: l'accés del jovent mataroní a les dinàmiques ocioses pel que fa al seu grau d' «instructivitat/instrumentalitat» $\mathrm{o}$ «(re)creativitat» no hauria de ser substantivament diferent en funció de la seva adscripció ètnica ${ }^{17}$.

\section{Oci lícit, oci il.lícit}

No entenem com a activitats il.lícites en el temps lliure aquelles resistències rituals (De Martino) o respostes subculturals (Phil Cohen) que construeixen alguns joves i algunes joves per intentar expressar i resoldre, ni que sigui de forma «màgica», les contradiccions que romanen amagades en el si de la societat. Aquest tipus d'estratègies plantegen solucions a un nivell simbòlic, sense possibilitats reals de corroboració; però alhora ofereixen als nois i noies espais d'autonomia on poden desenvolupar algunes de les funcions que les institucions socials no poden acomplir de forma positiva; és a dir, la dotació d'identitat social.

Contràriament, i en un sentit ampli, definirem aquí les conductes il-lícites com aquells comportaments antisocials que tenen com a característica nuclear la violència física (que s'exerceix al mateix temps contra els objectes $\mathrm{i}$ les persones) i/o simbòlica (que s'exerceix contra les persones). Més enllà de la constitució d'una subcultura juvenil articulada al voltant d'un estil distin-

16. A partir d'aquí, insistim en el caràcter segregador del fenomen de l'oci i la seva dinàmica de (relativa) producció i reproducció de les desigualtats socials per assenyalar, finalment, com la realització d'activitats «instructives» per part dels joves més privilegiats econòmicament i culturalment reverteix precisament en aquest tipus de capital, concebut com una mena de "garantia de futur», mentre que la participació en dinàmiques menys formalitzades i/o allunyades de l'imaginari escolar permet als seus protagonistes guanyar, sobretot, en capital relacional (establint relacions de dependència i amistat amb membres de la seva mateixa condició socioeconòmica).

17. No es tracta tant de fer comparacions ni de col-locar en un mateix nivell dues realitats socials diferentment viscudes $\mathrm{i}$ amb conseqüències desiguals pel que fa a les possibilitats reals d'accés als capitals socials/relacionals, econòmics i culturals que el medi social ofereix. Del que es tracta, en canvi, és de cridar l'atenció sobre el fet que hi ha una sèrie d'activitats mercantilitzades prohibitives per aquelles famílies que no tenen unes disponibilitats econòmiques determinades (per exemple, les classes d'idiomes o d'informàtica, les classes de música o d'interpretació teatral), i que, almenys en aquest cas, no podem parlar de l'existència d'una barrera de classe entre la major part de les famílies d'origen immigrat i moltes de les autòctones que habiten en els barris semiperiferics de Mataró. Estem, per tant, d'acord amb la idea que la desigualtat produïda per raó d'ètnia és en bona mesura una subrogació de les desigualtats de base socioeconòmiques. 
tiu, el que diferencia les activitats il-lícites no és ja la contestació, sinó, sobretot, la frustració. En efecte, la gravetat de les accions il-lícites depèn, en un principi, del nivell on cadascú tingui establerts els límits d'acció, però convindria subratllar que, com a generació, els joves i les joves es troben en una societat de consum opressora en la qual la realitat econòmica és, per a ells i elles, més aviat precària i en què les instàncies tradicionals de socialització estan perdent progressivament el seu protagonisme.

Sota aquest punt de vista, les activitats il-lícites poden ser analitzades a partir de la confluència sinèrgica de tres processos de canvi que modifiquen profundament les condicions socials i les imatges culturals de la joventut i que s'analitzen a continuació:

- Escenari econòmic (capitalisme informacional i creixement sense ocupació): les condicions actuals de l'ocupació juvenil i la precarització de les condicions de treball d'ençà els anys vuitanta modifiquen de forma substantiva i radical la transició a la vida adulta dels joves i les joves. Els canvis no són simplement circumstancials, sinó que estem davant la irrupció d'un nou model social, identificat per Manuel Castells com «capitalisme informacional», que es caracteritza per un nou paradigma tecnològic que resulta ser molt excloent i dualitzador en relació amb el mercat de treball i generador de grans excedents de mà d'obra. Una realitat socioeconòmica tal no pot sinó tenir una influència negativa en la forma com els joves i les joves construeixen les seves expectatives, de manera que n'hi ha molts que s'aferren a patrons d'irresponsabilitat, d'insatisfacció, de desafecció social i racisme, etc. davant l'absència d'horitzons clars (i això dilata en molts casos la seva transició a la vida adulta).

- Cosmovisions (modernitat, pluralitat i crisi de sentit): com diuen Peter L. Berger i T. Luckmann, una de les característiques dels països occidentals — «aquéllos donde la modernización ha llegado más lejos y donde la forma moderna de pluralismo se ha desarrollado plenamente» - és que "los sistemas de valores y las reservas de sentido han dejado de ser patrimonio común de todos los miembros de la sociedad», de manera que «el individuo crece en un mundo en el que no existen valores comunes que determinen la acción en las distintas esferas de la vida, y en el que tampoco existe una realidad única idéntica para todos» (1997: 61). Davant d'aquesta situació, allò que troben molts nois i noies en el seu confús camí des del jo personal fins al jo social, des de la individualitat fins a la sociabilitat, és la convivència desordenada de múltiples racionalitats, totes les quals són legitimades i legitimadores que "posibilitan un tipo de conductas diferentes de las propias de otras épocas, cuestionantes del principio de autoridad y que deslegitiman su validez en la práctica» i que «predisponen a actuar de forma autónoma y al margen de los cánones establecidos, propiciando la aparición de actos vandálicos» (Hernando, 1996: 165).

- D'altra banda, la joventut es mou en el marc d'una societat de consum que, més que mai, ha entronitzat com a màxims valors d'aquest cicle de 
vida el consum i l'emulació, i on les dinàmiques de festa i diversió són imposades al jovent com unes pautes que cal seguir difícils de qüestionar. En el fons, aquests models de conducta poden arribar a representar per alguns nois i noies joves el reflex d'una societat despietada que els obliga a adaptar-se a uns arquetipus frívols i superficials. Situació que és susceptible de provocar frustració, angoixes i sentiments d'insatisfacció.

Aquest collage de significats es correspon en gran mesura amb la crisi general dels canals de socialització tradicionals, especialment dels haguts en el context de la institució familiar. En efecte, en una situació de simultaneïtat de marcs culturals i d'agents socialitzadors en la qual cap no gaudeix d'una posició hegemònica per la seva capacitat de legitimació, té poc sentit parlar d'un model de conducta referencial que eduqui els joves i les joves d'acord amb els estàndards acceptats socialment. Davant d'aquesta pèrdua del rol socialitzador de les institucions tradicionals, l'individu fa ús d'altres mecanismes de rearticulació i creació de sentit, de manera que adquireix protagonisme l'ambient social que l'envolta: la seva colla d'amics i amigues. Si tenim en compte que la lògica interna d'algunes d'aquestes colles és delictiva, serà facil que aquesta mimetitzi els seus membres. En aquest sentit, serà especialment en els moments d'oci quan s'evidenciarà de forma més clara aquest problema, la qual cosa donarà lloc a l'expressió de sentiments de desorientació, inconformisme $\mathrm{i}$ insatisfacció que poden cristal.litzar finalment en conductes antisocials i violentes.

Pel que fa al nostre objecte d'estudi, diríem que el conjunt d'aquests elements adopta la seva màxima crueltat en el cas de les segones generacions de famílies immigrades. En efecte, no només es tracta d'una població subalterna, relegada generalment a les posicions més baixes de la jerarquia social, sinó que, a més, ha experimentat de forma brusca el pas d'una cultura amb un sistema de valors relativament coherent i homogeni a una altra de caracteritzada pel seu pluralisme i per una filosofia hedonista (Bell) i de l'«I am me» (Mitchell). En aquest escenari, la descoberta que fan els nois i noies immigrats del cosmos com a conjunt de parcialitats pot provocar el desig de fugir dels determinismes imposats al llarg del seu procés de socialització, i això moltes vegades dóna lloc a l'esfondrament del model d'autoritat parental.

Fent novament èmfasi en la dimensió segmentadora de l'accés al consum d'oci, la idea que ha orientat les explicacions d'aquest punt en la nostra recerca centra l'atenció sobre la participació desigual del jovent magribí immigrat i del jovent mataroní autòcton en les dinàmiques d'oci lícites i il.lícites.

\section{Oci «masculi», oci "femeni»"}

Tradicionalment, la cultura juvenil, contingut que omple un període de transició irresponsable (des del punt de vista de l'imaginari de les obligacions adultes) per definició, ha estat entesa com una cultura bàsicament masculina. Participar activament en el consum d'un oci valorat en l'espai social juvenil 
implica gaudir de cert grau d'autonomia, d'irresponsabilitat, i les noies nombroses vegades continuen vivint el trànsit vers l'emancipació de la família d'origen com el pas d'una dependència domesticofamiliar a una altra. Quan l'Escola de Xicago estudiava els comportaments "anòmics» $\mathrm{i}$ "desviacionistes» de determinats grups de joves urbanites, quan Gramsci tracta d'explicar les diferents formes de dissidència i contestació juvenils atenent les crisis d'identitat i d'hegemonia de les noves societats capitalistes, quan De Martino dóna compte de les expressions de violència juvenil en tant que rituals de pubertat adreçats a la superació del perill del caos civilitzatori, quan Monod estudia els estils de vida i els sistemes simbòlics dels bloussons noirs, quan el CCCS de Birmingham analitza els rituals subculturals de grups com els mods, els skinheads, els teds o els rockers, i les seves relacions amb l'estructura social i les cultures parentals, en definitiva, quan les ciències socials han dirigit la seva atenció vers aquesta temàtica, sobretot han tingut al cap les expressions masculines de les cultures juvenils; de fet, sovint no han fet sinó aproximar-se a fenòmens, com el de l'emergència de bandes juvenils, que tanmateix poden ser estudiats en tant que intents d'afirmació de la pròpia virilitat (comportaments violents, estètiques dures i agressives, actituds masclistes, etc.).

En els darrers anys ha tingut lloc un doble procés per afavorir la recuperació de les manifestacions del consum femení d'oci: d'una banda, diverses autores (Wulff, Garber i McRobbie) han abordat l'anàlisi de les cultures ocioses juvenils segons si s'articulen en espais «invisibles» de sociabilitat (i on apareixen amb més freqüència noies que nois), d'altra banda, algunes joves s'han anat incorporant progressivament a la participació en dinàmiques de consum "públic» fins al moment monopolitzades pels nois - incorporació que sobretot ha tingut lloc a l'entorn d'estils més interclassistes o de classe mitjana, com els pretesament "contraculturals», però que també s'ha fet evident en la formació de les anomenades «tribus urbanes» (skins, heavies, punks, makiners, etc.).

Però el que encara avui no sembla qüestionable és el fet que majoritàriament les joves viuen el seu consum d'oci de manera diferent a com el viuen els joves. En relació amb aquest punt, hem tractat de recollir aquells aspectes que podien fer visible l'existència d'aquesta diferència en el cas de les segones generacions estudiades i que s'havien anat apuntant en el decurs de la redacció dels punts anteriors. Per aquest motiu, i per tal de valorar en quina mesura la diferència entre nois i noies és especialment significativa en el cas de la població magribina, hem hagut de comparar-la amb la diferència existent quant al consum d'oci entre els nois i les noies autòctons.

D'aquesta manera, i en vista de la informació obtinguda d'enquestes i entrevistes (i d'algun petit exercici d'observació de determinats espais d'oci), a la versió íntegra d'aquest informe hem provat de donar voltes sobre les tesis següients: 1) les noies magribines participen menys que els nois magribins (i que les noies autòctones) dels espais i els temps de l'oci que es consumeix fora de casa; 2) les noies magribines, quan consumeixen oci extradomèstic, ho fan de manera menys intercultural que els nois magribins (i també que les noies autòctones) i, per tant, en espais i temps més segregats, sovint familiaritzats (sortir 
a passejar amb cosines o fins i tot amb la mare); 3) les noies magribines, com els nois magribins, participen menys que els nois i les noies autòctons en activitats d'oci formalitzades properes a l'imaginari de l'educació obligatòria regla$\mathrm{da}$, i menys que els joves immigrats i els nois i noies autòctons en activitats d'oci no formalitzades i ben valorades en el context de l'espai social juvenil; finalment, 4) les noies magribines, en participar menys de les dinàmiques d'oci fora de casa, intercultural i informal, que els nois magribins, tenen moltes menys probabilitats que aquests de caure en la realització d'activitats il.lícites o delictives.

Hagués estat molt interessant encetar, a fi de comprovar aquestes constatacions, una feina sistemàtica de recerca de les raons de la seva causalitat. No obstant això, una tasca com aquesta excedia de molt les possibilitats del nostre treball, motiu pel qual ens hem hagut d'acontentar amb l'exposició raonada de l'estat de la qüestió i, en tot cas, amb la referència a l'existència d'una doble dinàmica o procés circular: els models familiars de socialització i transmissió dels rols genèrics tendeixen a afavorir la reclusió de les noies magribines en l'àmbit domèstic, alhora que la seva exclusió dels criteris de sociabilitat valorada en els camps del consum d'oci contribueix a consolidar aquesta reclusió. La circularitat d'aquest procés, doncs, perilla quan aquestes noies inicien un acostament significatiu als temps i als espais d'oci públic i intercultural. De vegades, menys de les que ens pensem, la presència d'aquest perill podrà comportar situacions de conflictivitat oberta en el si de les famílies; en altres casos, en la mesura que l'acostament tingui lloc de manera progressiva i allunyant-se de les dinàmiques juvenils d'oci més nocives (para-delictives), aquest podrà tenir lloc en el marc de la negociació típica entre pares/mares i fills/filles. I tot plegat tenint en compte aquells marcs familiars conservacionistes de les tradicions de les societats d'origen; i no totes les famílies magribines participen d'aquests marcs.

\section{A manera de tancament}

Per acabar voldríem plantejar una inquietud que se'ns ha suscitat al llarg del nostre treball. Si és cert que de la consecució de la inserció social de les segones generacions depèn la culminació del procés migratori de les famílies; en altres paraules, si és veritat que el propi destí de la immigració com a fenomen social està en funció del futur de la integració social de la descendència familiar: quins són els mecanismes a través dels quals la sociabilitat d'aquestes segones generacions aconsegueix arrossegar l'estabilització de les seves famílies en la societat receptora?

La idea inicial era la de tractar de fonamentar la tesi següent: la participació dels joves i les joves d'origen immigrat en les xarxes socials generades a l'escola i a l'espai d'oci juvenil incrementa les relacions que estableixen les seves famílies a nivell institucional, intragrupal i intergrupal, fet que pot afavorir la integració d'aquestes en la societat acollidora. Ara bé, en el decurs de la recerca, però, hem hagut d'anar reformulant aquesta intuïció a l'entorn d'un dubte que constantment ens assetjava: quin és el principal causant de la integració 
social de les famílies immigrades, el propi projecte migratori de construir una vida pròspera (socialment i econòmica) en un país estranger, o deixar-se portar pels efectes integradors derivats de la inserció dels fills i les filles en les xarxes de sociabilitat autòctones? I encara un altre motiu d'incertesa: fins a quin punt condiciona la situació legal i laboral dels pares i les mares la participació d'aquests nens i nenes en aquestes xarxes $i$, de retruc, en quina mesura, el fet que ho faci acaba per esfondrar les possibilitats futures d'integració familiar? Tot plegat ens ha dut a adoptar una solució de compromís, vàlida fonamentalment en el pla analític: des del moment en què, d'una banda, ens trobem davant d'un projecte migratori amb perspectives d'estabilització i assentament, i, d'altra banda, les famílies aconsegueixen normalitzar la seva situació legal i laboral, es creen les condicions perquè aquestes puguin veure's beneficiades de l'«efecte multiplicador» que sobre la integració social dels col-lectius immigrats pot derivar-se de la plena inserció de la descendència en la societat d'acollida.

Però tot plegat no són més que suposicions. Convindria realitzar una anàlisi molt més detinguda i intensiva d'aquest procés de manera que poguessin arribar a fer-se visibles els mecanismes, els canals, els itineraris concrets que permeten que les famílies d'origen magribí es beneficiïn de la integració social de la seva descendència. Caldria dur a terme històries de vida, estudis de la cronologia i l'evolució de les xarxes relacionals i dels guanys que d'aquestes es deriven a tots els nivells (legals, econòmics, culturals...), i un llarg etcètera. Tanmateix, atès que creiem que es tracta d'una temàtica d'enorme transcendència, sense l'estudi de la qual l'anàlisi del sentit de la inserció social de les segones generacions de famílies immigrades pot quedar coix, emplacem per a una altra ocasió el seu abordatge.

\section{Bibliografia}

Ajuntament de Barcelona (1998). Pla director de la politica de joventut. Barcelona. Ajuntament de mataró (1997). Els immigrants a la ciutat de Mataró. Pla de treball. Mataró.

- (1998). Estudi de la població de Mataró a 1 de maig de 1996. Mataró.

Apple, M.W.; WeISS, L. (eds.) (1983). Ideology and Practice in Schooling. Filadèlfia: Temple University Press.

Apple, M.W. (1986). Ideología y currículo. Madrid: Akal.

ARENES i SAMPERA, J. (1995). "La incorporació tardana al sistema educatiu de Catalunya». Escola Catalana, 322. «Interculturalitat i ensenyament» [número monogràfic]. Barcelona: Òmnium Cultural, p. 10-13.

BALIBAR, E.; WallerSTEIN, I. (1991). Raza, nación y clase. Madrid: Iepala.

BANKS, J.A. (1994). An introduction to multicultural education. Boston: Allyn and Bacon.

BARGACH, A. (1996). «El impacto psicosocial de la migración en la familia de origen del migrante». Ponència presentada en el Congrés Internacional de Salut Mental de Barcelona.

Berger, P. L.: LuCKMANn, T. (1997). Modernidad, pluralismo y crisis de sentido. La orientación del hombre moderno. Barcelona: Paidós Studio. 
Bernstein, B. (1988). Clases, códigos y control. Madrid: Akal.

Bonal, X. (1995). «El profesorado y el cambio educativo. Consideraciones teóricas y metodológicas». Papers, 47. Bellaterra: Universitat Autònoma de Barcelona, p. 131-153.

- (1998). Sociología de la educación. Una aproximación crítica a las corrientes contemporáneas. Barcelona: Paidós.

Bonal, X.; Tomé, A. (1997). «Metodologías y recursos de intervención». Cuadernos de pedagogía, 245. Barcelona, p. 56-69.

Bourdieu, P.; PASSERON, J.C. (1977). La reproducción. Elementos para una teoría del sistema de enseñanza. Barcelona: Laia.

CARBONELL, F. (1995). «Com s'hauria d'entendre la integració dels immigrants estrangers?». Escola Catalana, 322. «Interculturalitat i ensenyament» [número monogràfic]. Barcelona: Òmnium Cultural, p. 6-10.

- (1997). Immigrants estrangers a l'escola, Barcelona, Fundació Serveis de Cultura Popular i Editorial Altafulla.

CÁRITAS (1994). Documentación social, 27. «Interculturalidad» [número monogràfic]. Madrid: Cáritas.

CASAL, J. (1998). «Modalidades de transición profesional, mercado de trabajo y condiciones de empleo». Ponència presentada al congrés La nova condició juvenil i les polítiques de joventut. Balanç, realitats i noves perspectives. Barcelona, novembre de 1998. Diputació de Barcelona i Ajuntament de Barcelona.

CASTELlS, M. (1997). La era de la información. Madrid: Alianza.

Col-LeCTIU IOÉ (1994). Marroquins a Catalunya. Barcelona: ICEM-TEIM, Enciclopèdia Catalana

COL·LECTIU RONDA (1998). Immigració i estrangeria: l'estat de la qüestió. Barcelona: FUS. Col-lecció Finestra Oberta.

Delgado, M. (1998). Diversitat i integració. Barcelona: Empúries.

DÍAZ-AgUAdO, M.a J.; BARAJA, A. (1993). Interacción educativa y desventaja sociocultural. Un modelo de intervención para favorecer la adaptación escolar en contextos inter-étnicos. Madrid: Ministerio de Educación y Ciencia, CIDE.

DIPUTACIÓ DE BARCELONA (1997). II Informe sobre immigració i treball social. Barcelona: Diputació de Barcelona.

- (1998). Document de reflexió. La nova condició juvenil i les polítiques de joventut: cap a una proposta de polítiques afirmatives. Barcelona: Diputació de Barcelona.

Elias, N.; DunNing, E. (1992). Deporte y ocio en el proceso de la civilización. Madrid: Fondo de Cultura Económica.

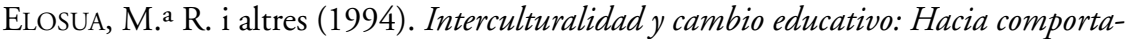
mientos no discriminatorios. Madrid: Ediciones Narcea.

FreIXA, C. (1998). De jóvenes, bandas y tribus. Barcelona: Ariel.

FUNES, J.; CAROL, J.L. (1998). Niños, niñas y adolescentes inmigrantes no comunitarios en España. Aproximación a sus principales dificultades. Treball inèdit.

Galland, O. (1998). «La joventut, una nova etapa de la vida». Ponència presentada al congrés La nova condició juvenil i les polítiques de joventut. Balanç, realitats $i$ perspectives. Barcelona, novembre de 1998. Diputació de Barcelona i Ajuntament de Barcelona.

Gil Calvo, E. (1985). Ocio y prácticas culturales de los jóvenes. Barcelona: Ministerio de Cultura.

- (1998). «EL "big bang" de la juventud: del relato a la red». Ponència presentada al congrés La nova condició juvenil i les polítiques de joventut. Balanç, realitats $i$ 
noves perspectives. Barcelona, novembre de 1998. Diputació de Barcelona i Ajuntament de Barcelona.

GIROUX, H.A.; FLECHA, R. (1992). Igualdad educativa y diferencia cultural. Barcelona: El Roure.

- (1990). Los profesores como intelectuales. Hacia una pedagogía crítica del aprendizaje. Barcelona: Paidós-MEC.

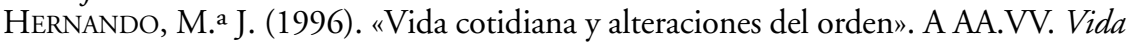
cotidiana y nuevas generaciones. Bilbao: Universidad de Deusto.

IHADDOUTEN, A. (1995) «El nen immigrant i el nou entorn social i escolar». Escola Catalana, 322. «Interculturalitat i ensenyament» [número monogràfic]. Barcelona: Òmnium Cultural, p. 18-20.

IzQUIERDO, A. (1996). La inmigración inesperada. La población extranjera en España (1991-1995). Valladolid: Editorial Trotta.

Jové I MONCLÚS, G. (1996). La diversitat cultural a l'escola. Lleida: Universitat de Lleida. KYMLICKA, W. (1995). Ciudadanía multicultural. Barcelona: Paidós.

LluCh, X. (1995). Educar desde el interculturalismo. Salamanca: Entre-pueblos i AMARU Ediciones.

MAFFESOLI, M. (1990). El tiempo de las tribus. Barcelona: Icaria.

Manyer, J. (1996). Quan l'Islam truca a la porta. Per a una aproximació cultural als musulmans de Catalunya. Barcelona: Fundació Serveis de Cultura Popular i Editorial Altafulla.

MarTínez, R.; Pérez, J.D. (1997). El gust juvenil en joc. Distribució social del gust específicament juvenil entre els estudiants de secundària de Terrassa. Barcelona: Diputació de Barcelona. Materials de Joventut.

MARTíneZ , R. (1998). «Formes de vida i cultura juvenil, avui. L'espai juvenil com a renovació social». Ponència presentada al congrés La nova condició juvenil i les politiques de joventut. Balanç, realitats $i$ noves perspectives. Barcelona, novembre de 1998. Diputació de Barcelona i Ajuntament de Barcelona.

McCARTHY, C. (1994). Racismo y curriculum. Madrid: Ediciones Morata i Fundación Paideia.

NARbONA, L.M. (1993). Marroquies en Viladecans. Una aproximación al tema de la inmigración. Barcelona: Ajuntament de Viladecans.

OfFe, C. (1994). Las contradicciones en el Estado del Bienestar. Madrid: Alianza Universidad.

PAJARES, M. (1998). La inmigración en España. Retos y propuestas. Barcelona: Ministerio de Trabajo y Asuntos Sociales. Colección Icaria Antrazyt.

Rex, J. (1983). Race Relations in Sociological Theory. Londres: Routledge and Kegan Paul.

RoQuÉ, M.a À. (ed.) (1994). Les cultures del Magreb. Barcelona: ICEM, Enciclopèdia Catalana.

- (ed.) (1998). Valors i diversitat cultural a les societats d'Europa i del Magreb. Barcelona: ICEM.

Ruiz Olabuénaga, J.I. (1996). «Los estilos de vida como legitimidad ética de la disidencia y de la infracción social». A AA.VV. Vida cotidiana y nuevas generaciones. Bilbao: Universidad de Deusto.

SANROMÁN, T. (1992). «Pluriculturalidad y marginación». A AA.VV. Sobre interculturalidad. Girona: Fundació SER.GI. - Programa TRAMA.

SCHÜTZ, A. (1974). «El forastero. Ensayo de psicología social». Estudios sobre teoría social. Buenos Aires: Editorial Amorrortu. 
SiguÁn, M. (1998). La escuela y los inmigrantes. Barcelona: Paidós Educador.

STOLCKE, V. (1994). «Europa: nuevas fronteras, nuevas retóricas de exclusión». A AA.VV. Extranjeros en el paraíso. Bacelona: Editorial Virus.

Touraine, A. (1971). «Trabajo, ocios y sociedad». A AA.VV. Ocio y sociedad de clases. Barcelona: Editorial Fontanella.

Wieviorka, M. (1992). El espacio del racismo. Barcelona: Paidós.

Willis, P. (1998). Cultura viva. Una recerca sobre les activitats culturals dels joves. Barcelona: Diputació de Barcelona. Materials de Joventut.

- (1988). Aprendiendo a trabajar. Madrid: Akal. 